\title{
Las lúnulas de la necrópolis de la Edad del Hierro de El Castillo (Castejón, Navarra)
}

\section{Crescentic plaques of the Iron Age necropolis of El Castillo (Castejón, Navarra)}

\author{
José Antonio Faro Carballa ${ }^{1}$
}

UNED

\begin{abstract}
RESUMEN
El presente artículo aborda el estudio de las lúnulas halladas en la necrópolis de El Castillo (Castejón, Navarra). Proceden de tumbas fechadas entre la segunda mitad del siglo vi y el siglo III a. C. Estos objetos están escasamente representados en los yacimientos de la Edad del Hierro. El conjunto analizado es el más numeroso de los documentados en la Península Ibérica.
\end{abstract}

\section{SUMMARY}

This article addresses the study of crescentic plaques found in the necropolis of El Castillo (Castejon, Navarra). They come from tombs dated between the second half of the sixth century and the third century BC. These objects are poorly represented at the sites of the Iron Age. The group analyzed is the largest of documented in the Iberian Peninsula.

PALABRAS CLAVE: necrópolis de El Castillo; valle medio del Ebro; Edad del Hierro; lúnulas.

KEY WORDS: necropolis of El Castillo; Middle Ebro valley; Iron Age; crescentic plaques.

CÓMO CITAR ESTE ARTÍCULO / CITATION: Faro Carballa, J. A. 2017: "Las lúnulas de la necrópolis de la Edad del Hierro de El Castillo (Castejón, Navarra)". Archivo Español de Arqueología, 90: 171-193. doi: 10.3989/aespa.090.017.008

\section{INTRODUCCIÓN}

Los objetos de indumentaria y adorno aportan una información esencial para el conocimiento de las sociedades protohistóricas. La función del vestido no se limitaba a la protección del cuerpo frente a factores de tipo climático o medioambiental. Al igual que los elementos de adorno, también era un reflejo de valores

\footnotetext{
${ }^{1}$ j.antoniofaro@gmail.com / ORCID iD: http://orcid.org/000 0-0003-1203-3734
}

jerárquicos, políticos, económicos, religiosos, estéticos, etc. (Sousa 2007: 23). Este propósito todavía resulta más evidente en contextos ritualizados, como es el caso de las necrópolis.

Los tejidos, por su condición de materiales orgánicos, no han dejado huella en el registro arqueológico. Sin embargo, sí se documentan elementos metálicos que, al margen de su valor estético, se encontraban directamente relacionados con la vestimenta. El número de ejemplares identificados en la necrópolis de El Castillo es de 296, lo que indica que se trata de piezas ampliamente representadas en los rituales funerarios. De ellas, 155 corresponden a fíbulas, 1 a un broche anular, 26 a broches de cinturón, 14 a láminas de refuerzo de los citados cinturones, 34 a grapas, 50 a botones y 16 a lúnulas.

Los testimonios aportados por las fuentes escritas e iconográficas subrayan el papel otorgado a la indumentaria como elemento de distinción social, que alcanzaba su expresión máxima en las ceremonias de carácter sacro, entre las que se incluyen los actos fúnebres. En este contexto, las lúnulas deben ser consideradas como objetos de difícil acceso, por el valor intrínseco de los materiales utilizados y por la destreza técnica que requería su elaboración. Al margen de cuestiones estéticas, se les atribuye connotaciones de carácter simbólico-religioso y actuaban como elementos de prestigio que indicaban el estatus de su poseedor. Asimismo, la ausencia de armas en las tumbas con lúnulas y su reiterada asociación con determinados elementos de adorno muestran, como veremos en este artículo, una pauta probablemente relacionada con cuestiones de género. Aunque, como bien señala I. Izquierdo, estas vinculaciones entre ajuar y género deben ser investigadas en profundidad y no asumidas (Izquierdo 2007: 253). 


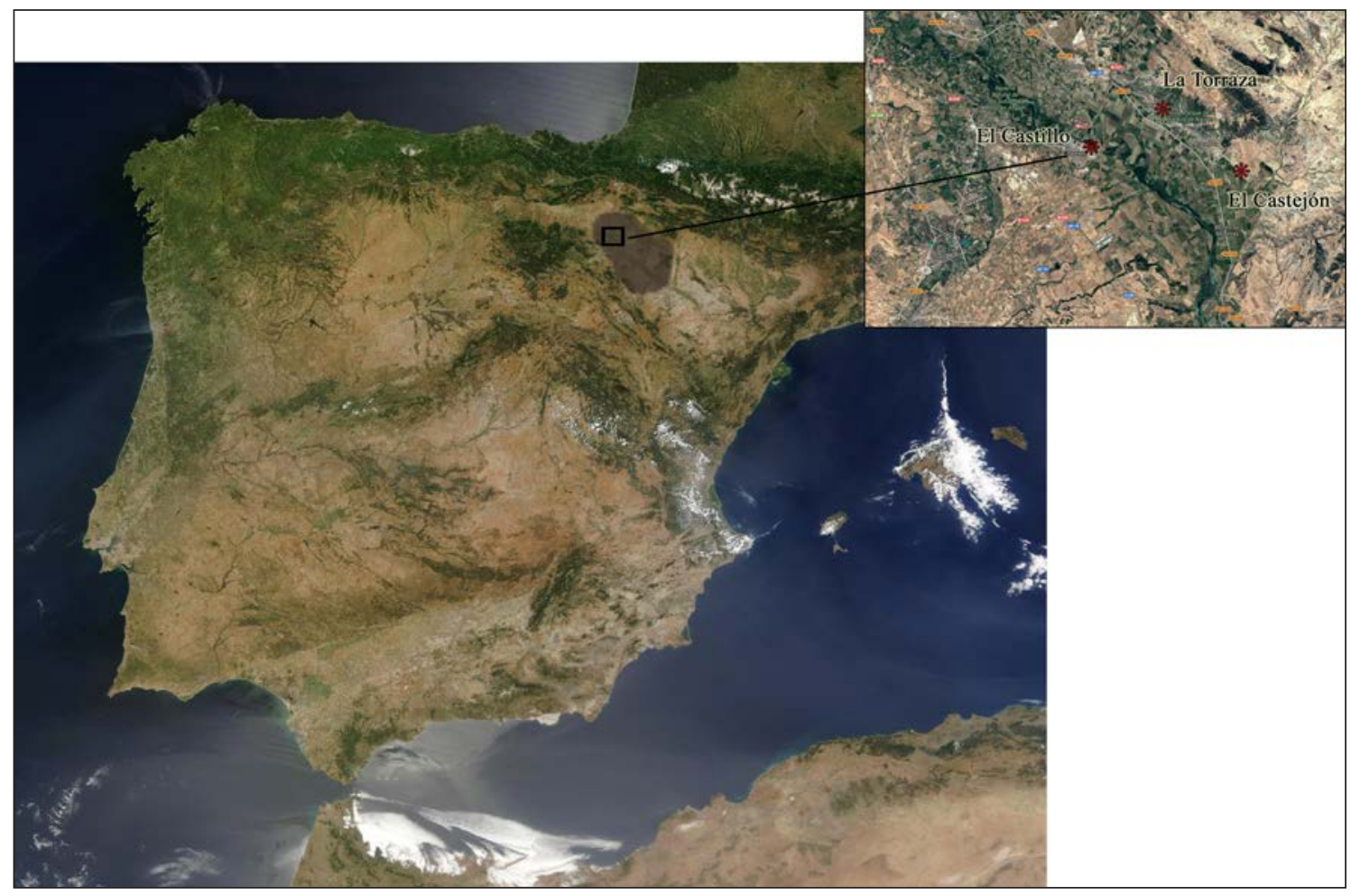

Figura 1. Valle medio del Ebro. Necrópolis de incineración protohistóricas situadas en su extremo occidental.

Las lúnulas son objetos con forma de creciente lunar elaborados sobre láminas delgadas, generalmente en metales preciosos como el oro y la plata. Dependiendo de la presencia o de la ausencia de remates o terminaciones han sido interpretadas como collares y, en ocasiones, como pectorales. Suelen estar decoradas con motivos geométricos o figurados que se realizaron mediante el empleo de técnicas como el troquelado, el repujado, el puntillado o la incisión. Estas piezas se documentan sobre todo en el extremo occidental de Europa, a lo largo del III y II milenio a. C. El mayor número de ejemplares se registra en Irlanda y Gran Bretaña durante el Bronce Antiguo. En la Península Ibérica, corresponden a esta etapa algunas piezas halladas en Galicia y el norte de Portugal (Almagro-Gorbea 1995; García-Vuelta y Armada 2003). A partir del Bronce Final la proporción de lúnulas desciende de forma significativa, probablemente por el apogeo de los torques, y comienzan a fabricarse en metales menos valiosos como el bronce. Pese a ello, las lúnulas no deben considerarse como exclusivas del Calcolítico y de la Edad del Bronce. Su origen se remonta al Neolítico y continuaron utilizándose durante toda la Edad del Hierro hasta que, finalmente, fueron asimiladas por la cultura romana. Las propiedades profilácticas atribuidas a las lúnulas explican su representación en amuletos y en insignias del ejército romano.

La singularidad de estas piezas y las dificultades que plantean la identificación y la recuperación de este tipo de materiales justifican, en parte, la escasez de datos y la falta de investigación. No existen corpus o estudios de conjunto que analicen las lúnulas localizadas en la Península Ibérica. En este sentido, debemos recordar que el conjunto que aquí presentamos es el más numeroso de cuántos se conocen hasta la fecha y el que procede de un contexto arqueológico más fiable y preciso.

\section{LA NECRÓPOLIS DE EL CASTILLO Y SU CONTEXTO}

La necrópolis de El Castillo se localiza en el extremo occidental del valle medio del Ebro, al norte del municipio de Castejón, una circunscripción situada en el límite territorial que marca la frontera entre la Comunidad Foral de Navarra y La Rioja (Fig. 1).

El yacimiento se extiende por la terraza inferior de la margen derecha del río Ebro, al sureste del cerro de El Castillo, donde se ubicó el poblado. La distancia que separa ambos espacios es de apenas 


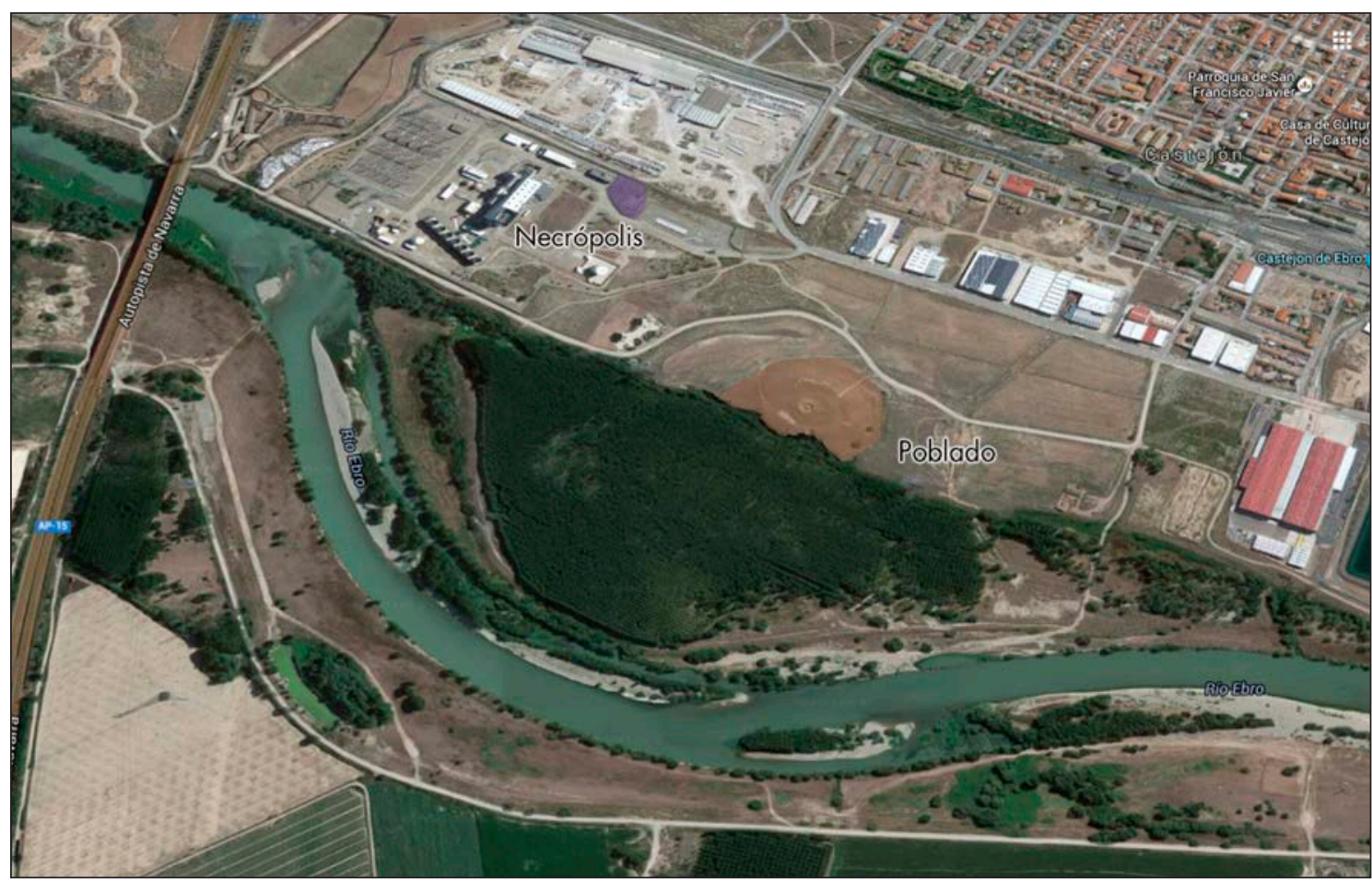

Figura 2. Poblado y necrópolis de El Castillo (Castejón, Navarra).

$450 \mathrm{~m}$, lo que denota la intención por parte de la población viva de incorporar a su contexto social el lugar donde reposaban sus antepasados.

La imagen actual del entorno de la necrópolis difiere significativamente del aspecto que debieron tener estos parajes en época protohistórica. La explotación de los terrenos con fines agrarios y, en fechas recientes, la construcción de dos centrales térmicas de ciclo combinado y de un polígono industrial, han modificado sustancialmente el paisaje (Fig. 2).

El trazado sinuoso del Ebro y del lento fluir de sus aguas, como consecuencia de una interminable sucesión de meandros, conformaron el escenario más propicio para franquear el cauce. No en vano la principal fuente de ingresos de la localidad de Castejón, hasta la llegada del ferrocarril en la segunda mitad del s. XIX, provenía de la tasa cobrada a los viajeros por el paso en una barca de una orilla a otra del Ebro (García Paredes 2002: 20). Las condiciones geoestratégicas de este enclave, controlando el vado del río y las rutas comerciales, son elementos claves para entender el grado de desarrollo social y económico alcanzado por esta comunidad.

Las cuestiones referentes al entorno geográfico, al desarrollo de las intervenciones arqueológicas y a las características de la necrópolis ya han sido extensamente tratadas en anteriores artículos a los que nos remitimos (Faro et alii 2002-2003: 45-77; Faro y Unzu 2006: 145-166; Faro 2015: 31-35).

El espacio funerario ocupaba una amplia superficie, que pudo superar las 2 ha. Sin embargo, el área no roturada, donde las estructuras funerarias (e. f.) mantenían su disposición original, se limitaba a una parcela de, aproximadamente, $3.000 \mathrm{~m}^{2}$. Presentaba el aspecto de una pequeña loma artificial, como resultado de la acumulación de las construcciones tumulares. Hasta la fecha se ha intervenido en una tercera parte de su superficie. El número total de estructuras funerarias identificado y delimitado es de 194, aunque el proceso de excavación y registro solo se ha completado en 178. De ellas 119 se encontraban ubicadas en el área no roturada del cementerio (Faro 2002; Faro et alii 2002-2003; Faro y Unzu 2006) (Fig. 3).

Las tumbas de El Castillo constituyen conjuntos cerrados, con materiales que pueden seriarse y fecharse con una cronología relativa que, a su vez, se puede contrastar con la que proporciona la estratigrafía. Las superposiciones, reutilizaciones e intrusiones observadas en el desarrollo de la excavación, a través de la estratigrafía, han permitido establecer una secuencia de los conjuntos. Se han identificado tres fases cronológicas para las 119 sepulturas halladas en el área intacta de la necrópolis (Fig. 4) (Faro 2015: 35-42). 


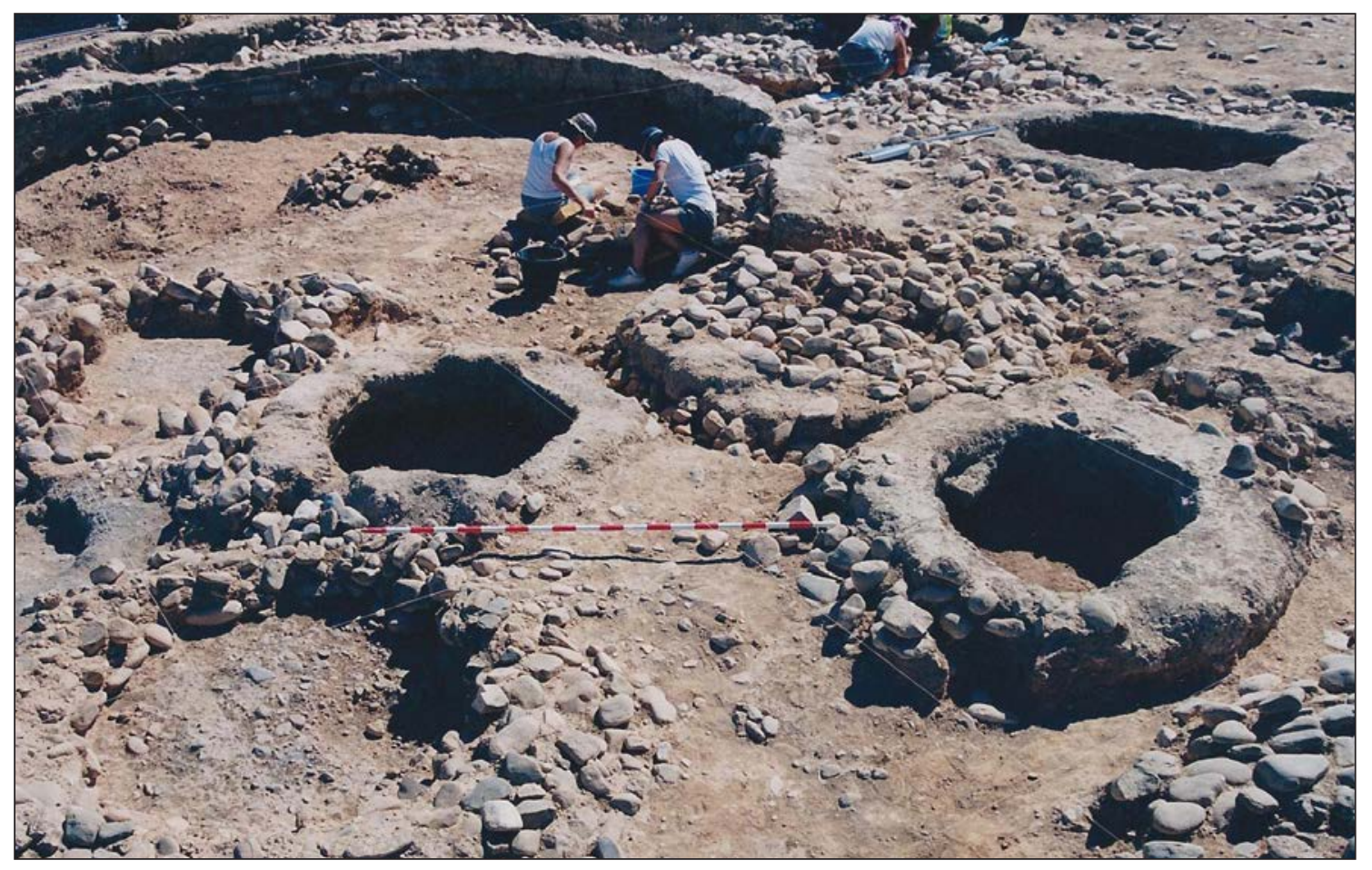

Figura 3. Aspecto que presentaba la necrópolis durante la intervención arqueológica. Campaña 2000 (Foto Gabinete Trama S. L.).

\section{LÚNULAS}

\subsection{Catálogo de las piezas}

En El Castillo se han identificado 16 lúnulas que fueron depositadas en el interior de nueve sepulturas del área intacta de la necrópolis (e. f. 28, 46, 123, $149,152,154,155,170$ y 174), lo que equivale a su presencia en el 7,56\% de las tumbas (Fig. 5). En la mayoría de las sepulturas se recuperó una única pieza, exceptuando los tres ejemplares hallados en la e. f. 149 y los seis identificados en la e. f. 152. El metal utilizado en la fabricación de estos objetos es el bronce y las láminas tienen, en todos los casos, espesores iguales o inferiores a $1 \mathrm{~mm}$. Ocho de las lúnulas están completas o se ha podido reintegrar la mayor parte de su estructura y las otras ocho se encuentran fragmentadas. En su estado de conservación ha influido de forma decisiva la exposición al fuego de la pira funeraria. Al tratarse de piezas que tienen como soporte láminas muy delgadas, el calor ha causado alteraciones muy significativas en su morfología original. Algunos ejemplares quedaron totalmente fragmentados y otros sufrieron importantes deformaciones. El resultado del proceso es un material frágil que puede aparecer fracturado y diseminado en cientos de pedazos, lo que dificulta en gran medida las labores de extracción e identificación de las piezas. Esta circunstancia, unida al carácter exclusivo de este tipo de objetos, justifica, en parte, la escasez de referencias en las necrópolis del valle medio del Ebro y, en general, de todo el ámbito peninsular. También justifica la existencia de múltiples interpretaciones ya que, con frecuencia, los fragmentos de lúnulas suelen aparecen en los inventarios clasificados como apliques, placas decoradas, diademas, etc.

En lo que hace referencia a las dimensiones, las lúnulas de El Castillo tienen longitudes máximas que oscilan entre los $18 \mathrm{~cm}$ de los ejemplares 154.22 y 170.8 y los $35 \mathrm{~cm}$ de una de las piezas halladas en la e. f. 149. La anchura máxima oscila entre los 2,6 $\mathrm{cm}$ de los ejemplares 46.6 y 123.4 y los $8 \mathrm{~cm}$ de la pieza 152.63.

Estas piezas, como se ha indicado anteriormente, destacan por su carácter simbólico-religioso y por su riqueza decorativa. Todos los ejemplares catalogados presentan decoración, con motivos realizados mediante las técnicas de repujado y/o de troquelado. Predominan los elementos geométricos (líneas de puntos, círculos concéntricos, triángulos, rombos, etc.), aunque también se recuperaron dos lúnulas excepcionales con decoración figurada (152.63 y 152.64).

El conjunto recuperado en la necrópolis de El Castillo es el más numeroso de los hallados hasta 


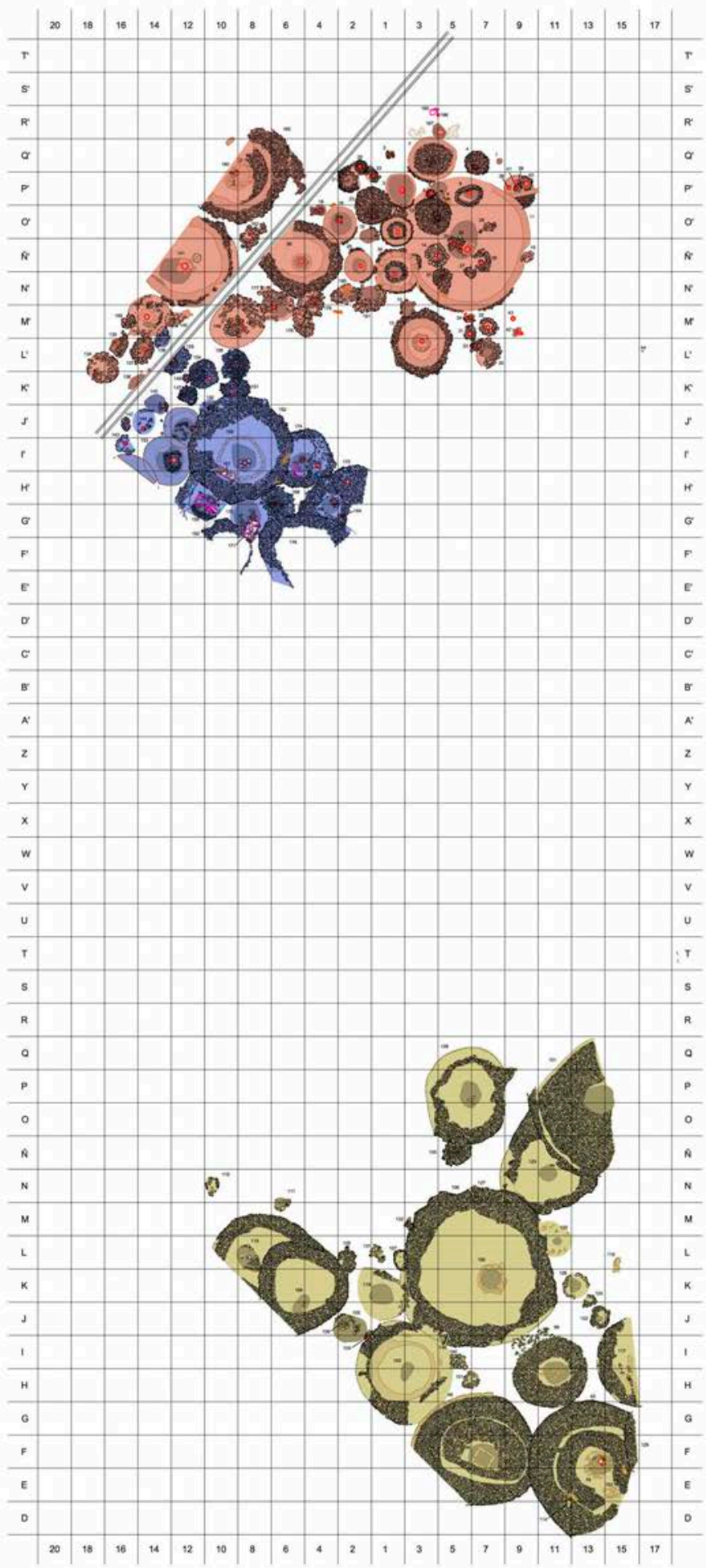

(1)

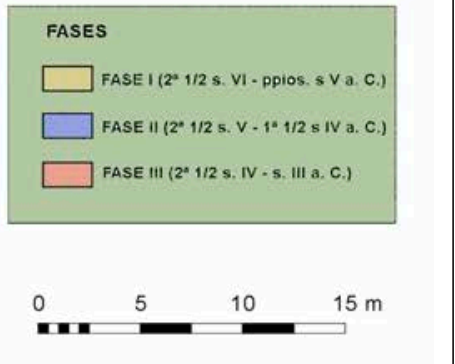

Figura 4. Necrópolis de El Castillo. Planimetría con la situación de las estructuras funerarias (Faro et alii 2002-2003: 53, modificada). 


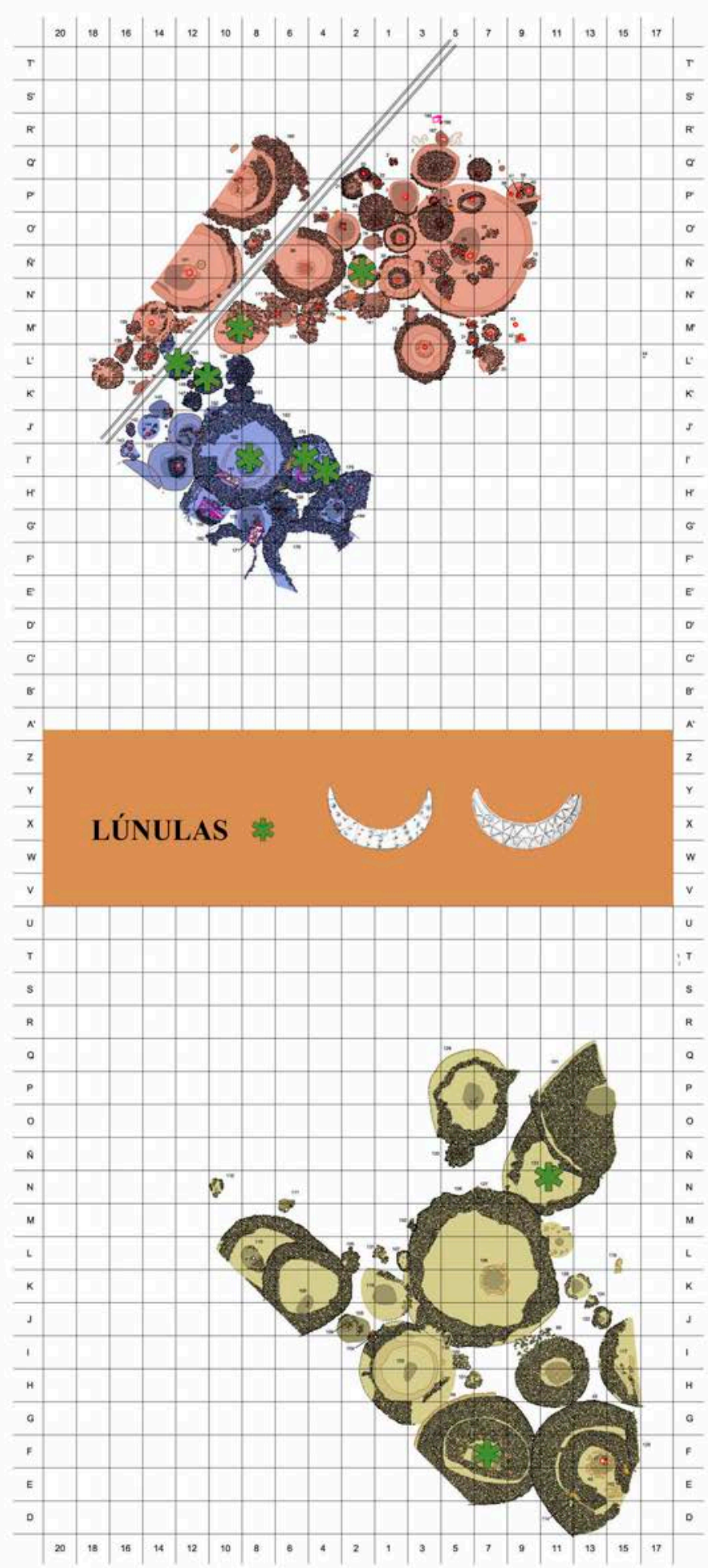

(1)
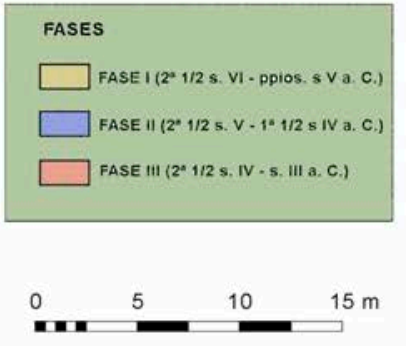

Figura 5. Plano del área intacta de la necrópolis de El Castillo con la dispersión de las lúnulas. 


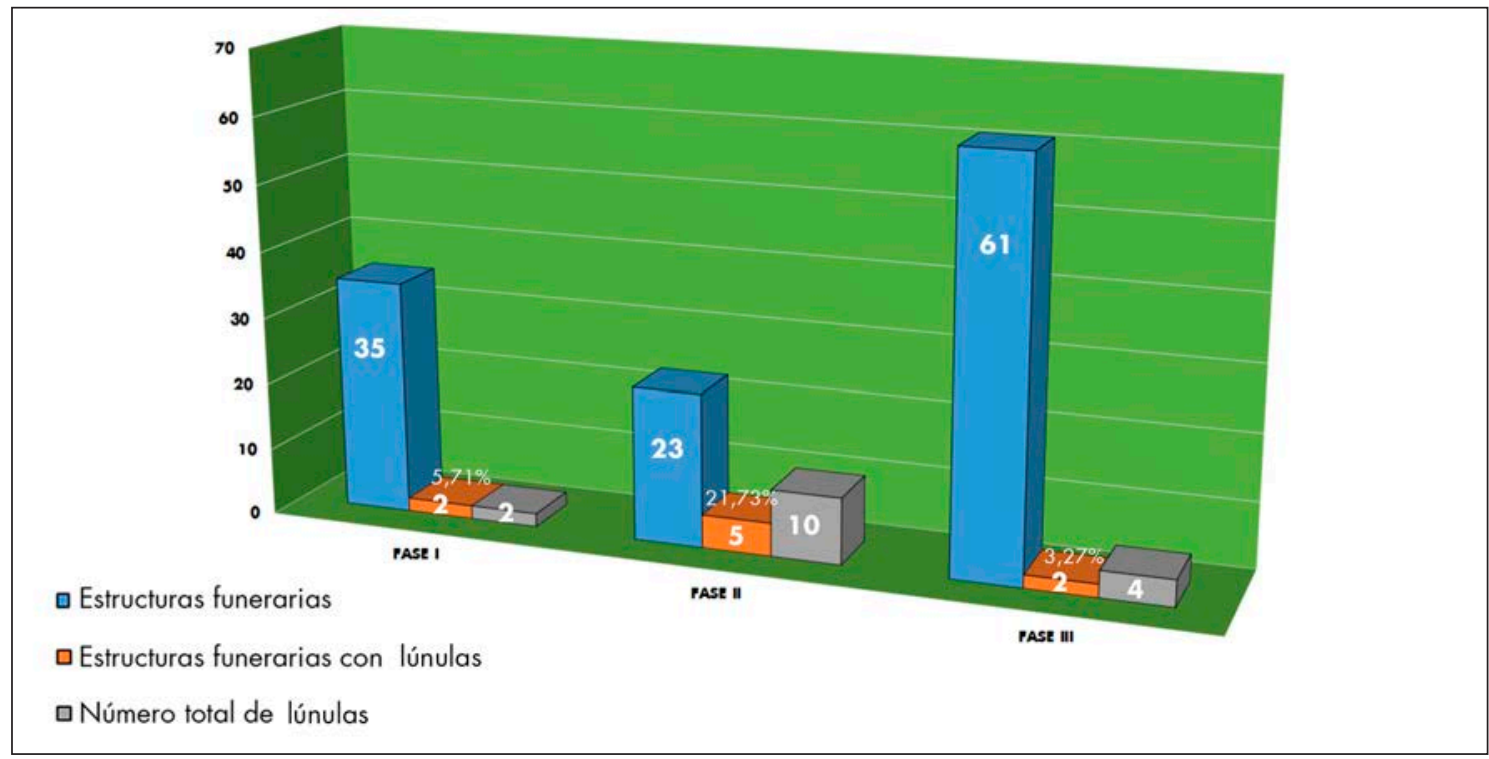

Figura 6. Distribución de las lúnulas identificadas en la necrópolis de El Castillo por fases.

la fecha en territorio peninsular y evidencia la perduración de estos objetos y su uso en los rituales funerarios del valle medio del Ebro durante la Edad del Hierro. Se documentan en sepulturas de las tres fases de ocupación identificadas en la necrópolis. La distribución de los ejemplares indica la existencia de algunas variaciones significativas (Fig. 6).

Fase I ( $2^{a} 1 / 2$ s. VI-principios s. V a. C.)

A esta etapa corresponden las lúnulas asociadas a las e. f. 46 y 123, lo que equivale a su uso en el $5,71 \%$ de las tumbas clasificadas en esta fase. En este período las lúnulas son más estrechas y la decoración se limita a una línea de puntos repujados delimitando el contorno de las piezas.

Lúnula 46.6: depositada en el interior de un recipiente de materia orgánica utilizado como urna, junto con otros objetos que formaban parte de la indumentaria del individuo incinerado, como un broche de cinturón de escotaduras abiertas y un garfio, un torques de junco macizo y terminales en forma de tampones o una fíbula de pie vuelto de tipo navarro-aquitano. Tiene $30 \mathrm{~cm}$ de longitud y una anchura máxima de 2,6 cm. Conserva ocho pequeñas perforaciones, de entre 1 y 1,5 $\mathrm{mm}$ de diámetro para la sujeción al vestido, una de ellas situada en uno de los extremos de la lúnula. Presenta decoración geométrica repujada, con una sencilla línea de puntos delimitando el contorno de la pieza (Fig. 7). Diseños similares, aunque realizados con técnica de puntillado, también se documentan en algunas lúnulas de oro de la Edad de Bronce, como la de Cabeceira de Bastos (Braga, Minho) (Comendador 1998: 49, fig. 48).

Lúnula 123.4: hallada en el interior del depósito de cenizas, formando parte de un ajuar austero, donde también destaca un pequeño vasito de ofrendas que presenta restos de decoración grafitada. La pieza está

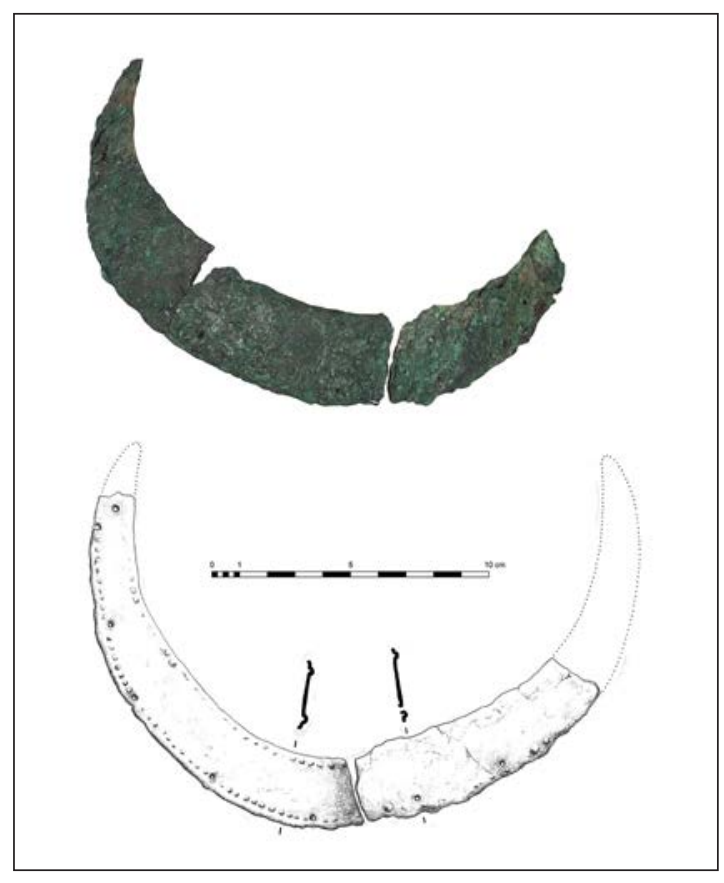

Figura 7. 46.6. Lúnula (Foto Gabinete Trama S. L.). 
incompleta, únicamente se ha recuperado un fragmento de uno de los extremos, de $12 \mathrm{~cm}$ de longitud y 2,6 cm de anchura máxima (Fig. 8). Conserva una de las perforaciones situadas en los extremos, de $2 \mathrm{~mm}$ de diámetro. Sin embargo, a diferencia del resto de las lúnulas catalogadas, no contaba con perforaciones en el borde inferior de la pieza. La decoración es similar a la descrita en el ejemplar 46.6 (Fig. 9).

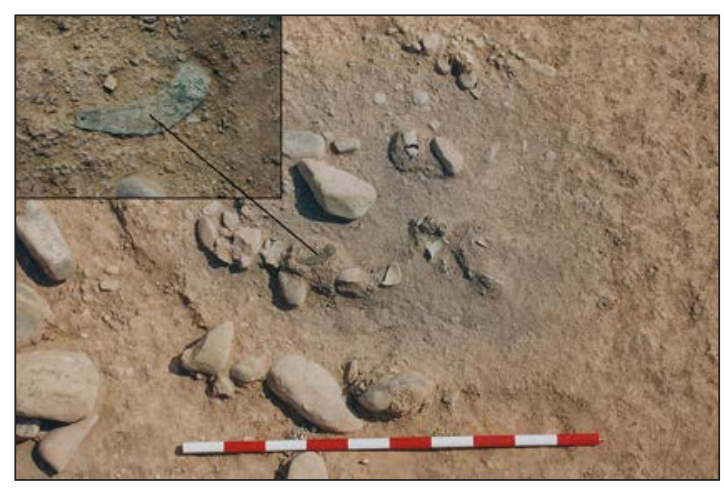

Figura 8. E.F. 123. Identificación de un fragmento de lúnula (123.4) en el depósito de cenizas (Foto Gabinete Trama S. L.).

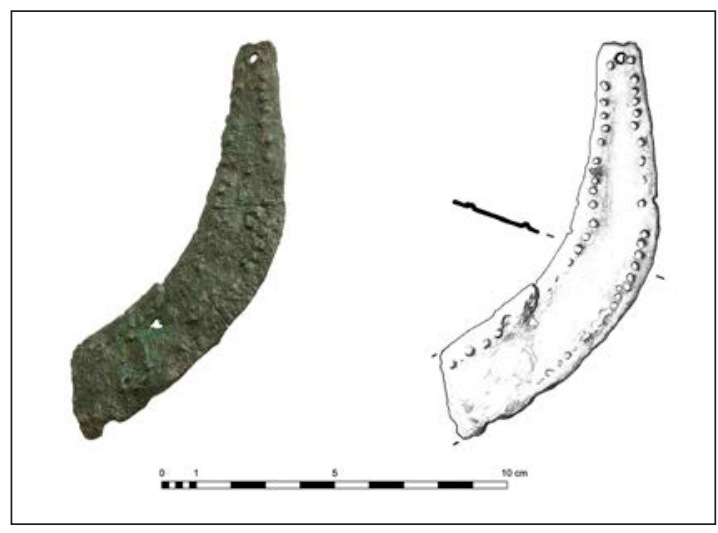

Figura 9. 123.4. Fragmento de lúnula (Foto Gabinete Trama S. L.).

Fase II $\left(2^{a} 1 / 2\right.$ s. V $-1^{a} 1 / 2$ s. IV a. C. $)$

En esta etapa se han documentado diez lúnulas asociadas a cinco enterramientos (e. f. 152, 154, 155, 170 y 174), lo que equivale a su uso en el $21,73 \%$ de las tumbas clasificadas en este período. Este porcentaje es el más elevado de las tres fases. En este periodo las lúnulas tienen una presencia más destacada en los ajuares y se diversifican las técnicas y las temáticas decorativas.

La e. f. 152 es el enterramiento de arquitectura más compleja, de mayores dimensiones y con el ajuar más destacado de todos los túmulos excavados de la Fase II. En esta tumba se han identificado seis lúnulas y la mayoría de los fragmentos fueron depositados en el interior del recipiente cerámico utilizado como urna, junto a piezas de vajilla metálica, objetos de adorno y otros elementos que formaban parte de la indumentaria (Fig. 10).

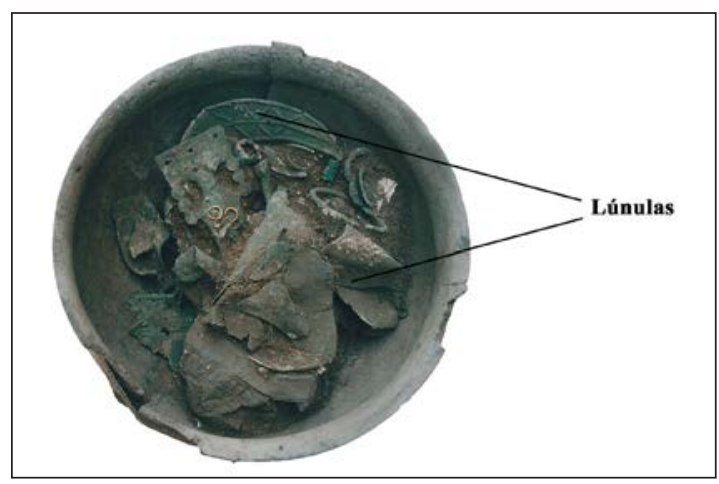

Figura 10. Lúnulas depositadas en el interior de la urna de la e.f. 152 (Foto Gabinete Trama S. L.).

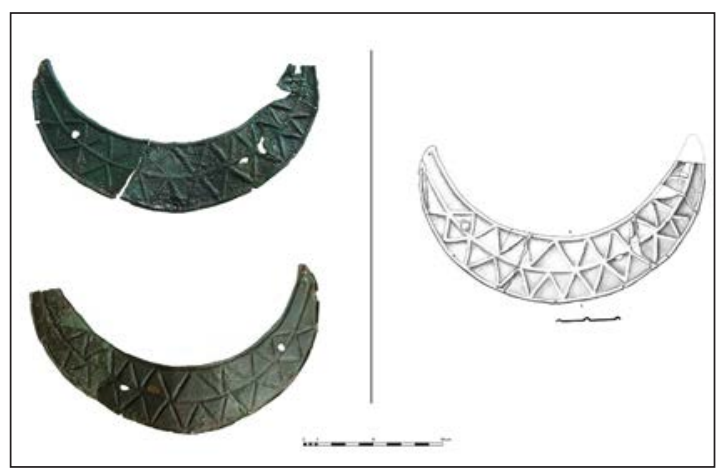

Figura 11. 152.23 Lúnula con decoración geométrica troquelada. Doble banda de triángulos (Foto Gabinete Trama S. L.).

Lúnula 152.23: es uno de los ejemplares mejor conservados de todo el conjunto. Tiene una longitud de $20 \mathrm{~cm}$ y una anchura máxima de $5 \mathrm{~cm}$. Todavía son visibles ocho pequeñas perforaciones de $1 \mathrm{~mm}$ de diámetro para la sujeción al vestido, una de ellas situada en uno de los extremos de la pieza. Presenta decoración geométrica troquelada, con tres líneas paralelas en resalte que crean dos espacios con bandas de triángulos (Fig. 11). En la simbología celta y celtibérica, las líneas quebradas representan el tránsito hacia el mundo celeste a través del mundo acuático, que actúa de puente permitiendo la purificación y el tránsito al Más Allá (Jimeno et alii 2004: 210; Lorrio y Sánchez de Prado 2009: 408). Aparecen con frecuencia en las placas articuladas con decoración figurada 
halladas en necrópolis celtibéricas como Carratiermes (Montejo de Tiermes, Soria) (Argente et alii 2001: 114), Numancia (Garray, Soria) (Jimeno et alii 2004: fig. 148) o Arcobriga (Monreal de Ariza, Zaragoza) (Lorrio y Sánchez de Prado 2009: fig. 176 y 178). Motivos triangulares también se documentan en las lúnulas esculpidas en alguna de las estelas diademadas de la Edad del Bronce, como es el caso de la estela de Granja Toniñuelo (Jerez de los Caballeros, Badajoz) (Bueno y Balbín 1997: fig. 23; Santos 2009: fig. 1.9), que se encuentra actualmente depositada en el Museo Arqueológico Nacional (Fig. 12).

Lúnula 152.40: tan sólo se conservan dos fragmentos, con una longitud total de $4,3 \mathrm{~cm}$ y $1,9 \mathrm{~cm}$ de anchura máxima, que formaban parte de uno de los extremos de la pieza. Presenta decoración geométrica troquelada, formada por una retícula de rombos (Fig. 13).

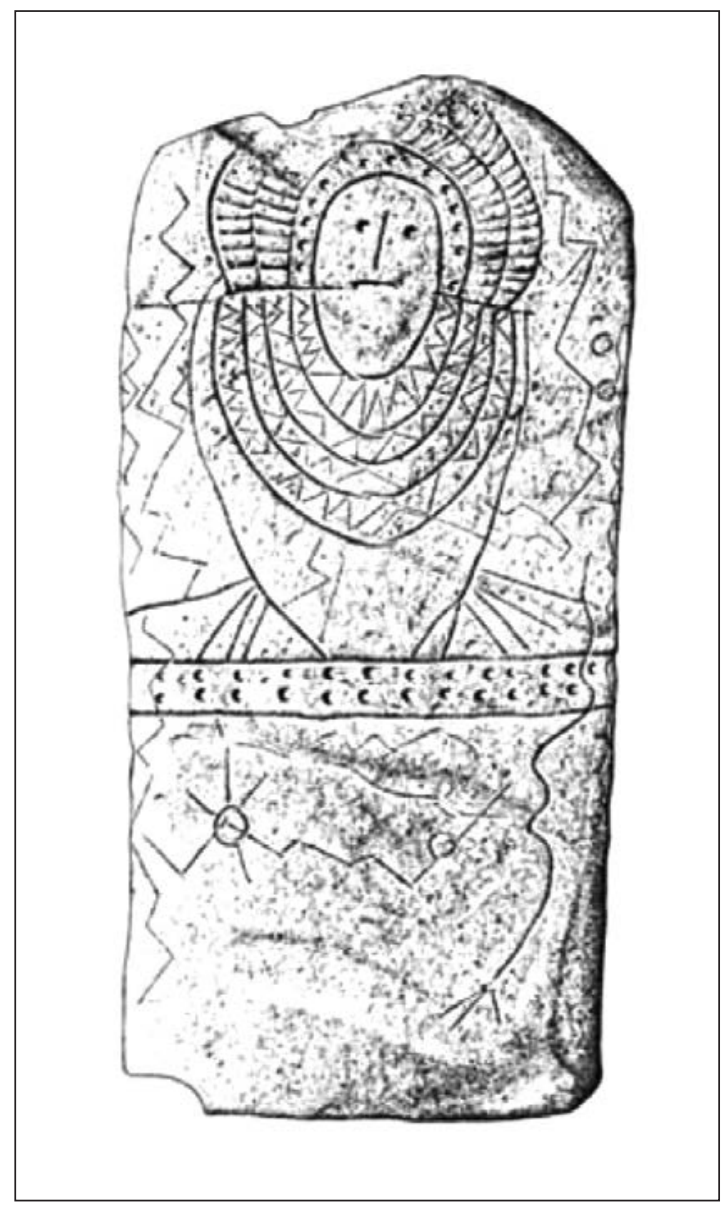

Figura 12. Estela diademada de Granja Toniñuelo (Jérez de los Caballeros, Badajoz). Lúnulas decoradas con motivos triangulares (Santos 2009: fig. 1.9).

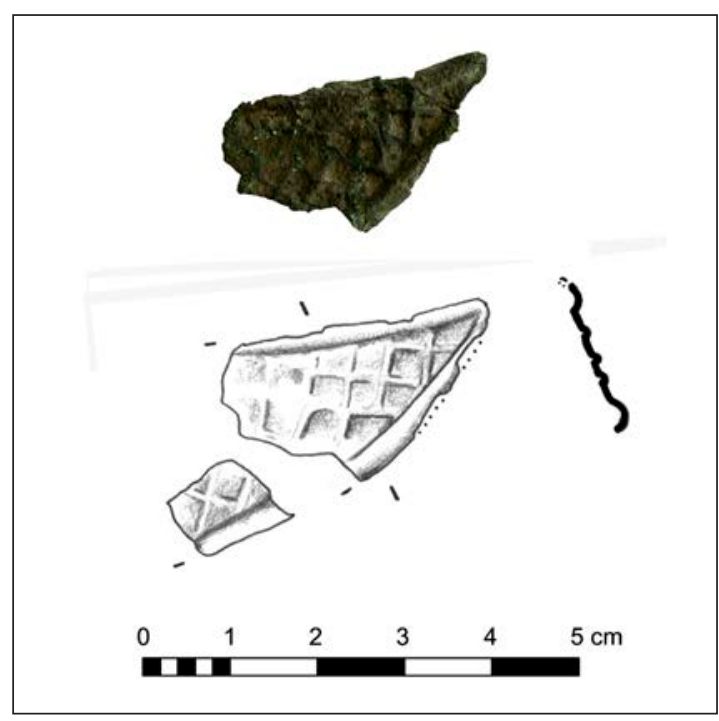

Figura 13. 152.40. Fragmento de lúnula con decoración geométrica de rombos (Foto Gabinete Trama S. L.).

Lúnula 152.63: fue diseñada para ser exhibida con el ejemplar 152.64, ambos se recuperaron juntos, en el interior del recipiente utilizado como urna cineraria. Las dos piezas se encontraban muy deformadas, como consecuencia de haber participado en el ritual de cremación ${ }^{2}$. Los efectos del calor también explican la ausencia de algunos fragmentos y el deterioro de la superficie del metal, debido al incremento de la oxidación. La lúnula 152.63 tiene una longitud de $29 \mathrm{~cm}$ y una anchura máxima de $8 \mathrm{~cm}$. Conserva en el borde inferior seis pequeñas perforaciones, de 1 mm de diámetro, para la sujeción al vestido. Presenta una decoración figurada, con una escena de temática agrícola obtenida mediante técnica de repujado.

Lúnula 152.64: tiene una longitud de $24 \mathrm{~cm}$ y una anchura máxima de $7 \mathrm{~cm}$. Conserva seis pequeñas perforaciones, de entre 1 y $2 \mathrm{~mm}$ de diámetro, para la sujeción al vestido, una de ellas situada en uno de los extremos de la lúnula. Presenta decoración figurada de temática cinegética (caza de ciervo), obtenida mediante técnica de repujado. En el apartado 3.3 se expone el estudio iconográfico de las escenas representadas en las lúnulas 152.63 y 152.64.

\footnotetext{
${ }^{2}$ La identificación y la reproducción gráfica de las escenas representadas en las lúnulas 152.63 y 152.64 , a causa de los efectos negativos del ritual de cremación, requirió de un proceso laborioso y de la aplicación de distintos sistemas fotográficos y digitales. En dicho proceso contamos con la inestimable colaboración del investigador y arqueólogo José Ignacio Royo Guillén y de su extensos conocimientos sobre iconografía y técnicas de grabado en la Edad del Hierro.
} 
Lúnula 152.65: no se ha podido reconstruir su estructura exacta. Conserva cinco fragmentos, uno de ellos se encontró fuera de la urna, en el depósito de cenizas. La longitud total de los trozos recuperados es de 21,4 cm y la anchura máxima de $4,5 \mathrm{~cm}$. En el borde inferior todavía se observan ocho perforaciones de $1 \mathrm{~mm}$ de diámetro para la sujeción al vestido. Presenta decoración geométrica repujada y troquelada, con la habitual línea de puntos delimitando el contorno de la pieza y al interior una única fila horizontal de círculos concéntricos (Fig. 14).

Lúnula 152.66: se ha recuperado un único fragmento, de $3,1 \mathrm{~cm}$ de longitud y $1,3 \mathrm{~cm}$ de anchura máxima, que formaba parte de uno de los extremos de la pieza. Presenta decoración geométrica troquelada con una línea en resalte delimitando el contorno de la pieza y, al interior, puntos repujados (Fig. 15).

Lúnula 154.22: formaba parte del ajuar de una pequeña tumba de encachado tumuliforme, que destaca por la variedad de piezas de indumentaria halladas en

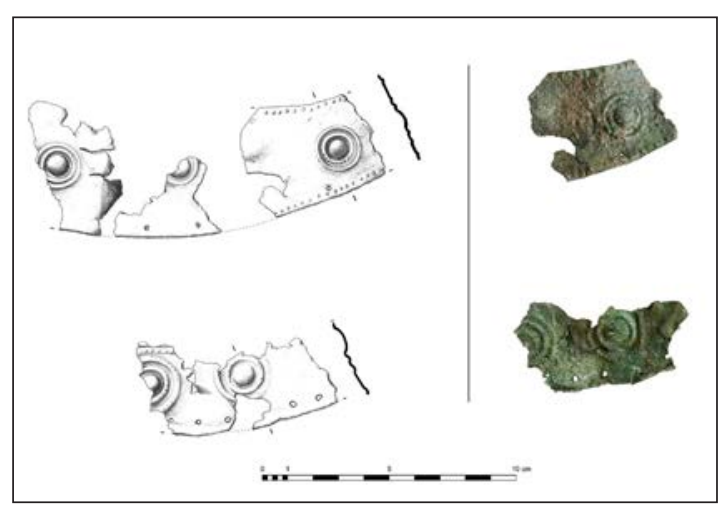

Figura 14. 152.65. Fragmentos de lúnula con decoración geométrica (Foto Gabinete Trama S. L.).

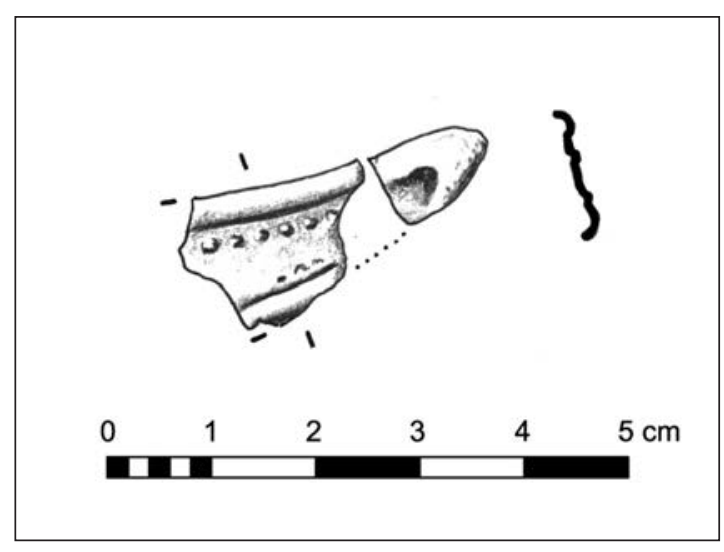

Figura 15. 152.66. Fragmento de lúnula (Foto Gabinete Trama S. L.). su interior (un broche de cinturón, tres fíbulas, una lúnula y un botón hemisférico). Se hallaron veintiséis fragmentos, los ocho de mayor tamaño han permitido reconstruir gran parte de su estructura. En origen tenía una longitud aproximada de $18 \mathrm{~cm}$ y una anchura máxima de $3 \mathrm{~cm}$. Conserva cuatro pequeñas perforaciones de entre 1 y $2 \mathrm{~mm}$ de diámetro para la sujeción al vestido, una de ellas situada en uno de los extremos de la lúnula. Al igual que el ejemplar 152.65, presenta decoración geométrica repujada y troquelada, con la habitual línea de puntos delimitando el contorno de la pieza y al interior una única fila horizontal de círculos concéntricos. La única particularidad es el hecho de combinar en los círculos las dos técnicas decorativas descritas, el troquelado para el motivo central y el repujado para definir el perímetro exterior (Fig. 16).

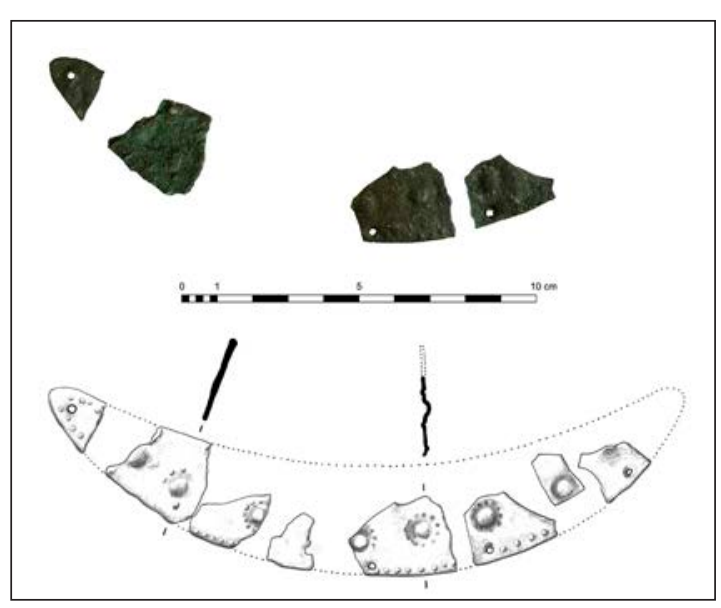

Figura 16. 154.22. Lúnula (Foto Gabinete Trama S. L.).

Lúnula 155.6: se hallaron sesenta pequeños fragmentos en el interior del recipiente utilizado como urna, sin que haya sido posible reconstruir su estructura. Presenta decoración geométrica repujada y troquelada, con una línea de puntos delimitando el contorno de la pieza y, al interior, círculos concéntricos (Fig. 17).

Lúnula 170.8: en el proceso de excavación se recuperaron cinco fragmentos de mayor tamaño y otros dieciocho de menores dimensiones, con los que se ha podido reconstruir su estructura. En origen tenía una longitud aproximada de $19 \mathrm{~cm}$ y una anchura máxima de $3,5 \mathrm{~cm}$. Conserva una perforación de 2 $\mathrm{mm}$ de diámetro en el borde inferior de la pieza para la sujeción al vestido. Presenta decoración geométrica repujada, con una sencilla línea de puntos delimitando el contorno de la pieza (Fig. 18).

Lúnula 174.5: depositada en el interior de la urna $\mathrm{y}$, de forma previa a su colocación en el contenedor 


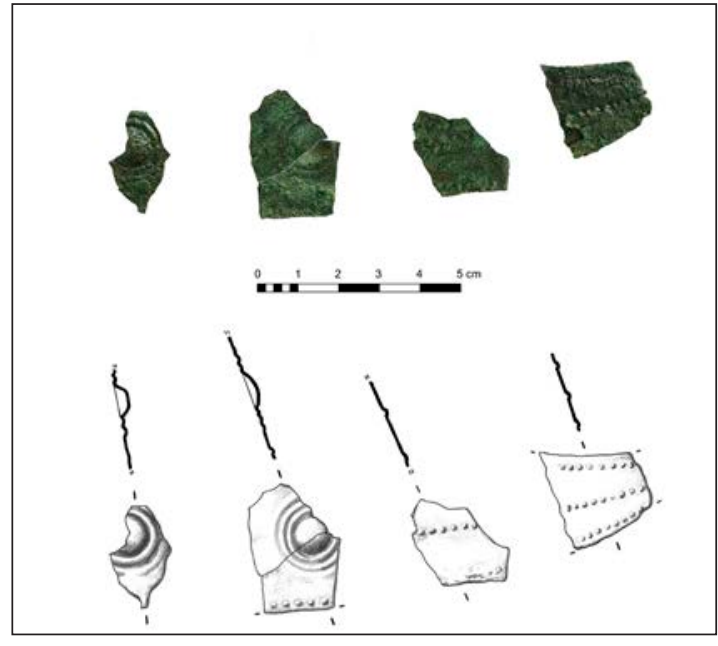

Figura 17. 155.6. Fragmentos de lúnula (Foto Gabinete Trama S. L.).

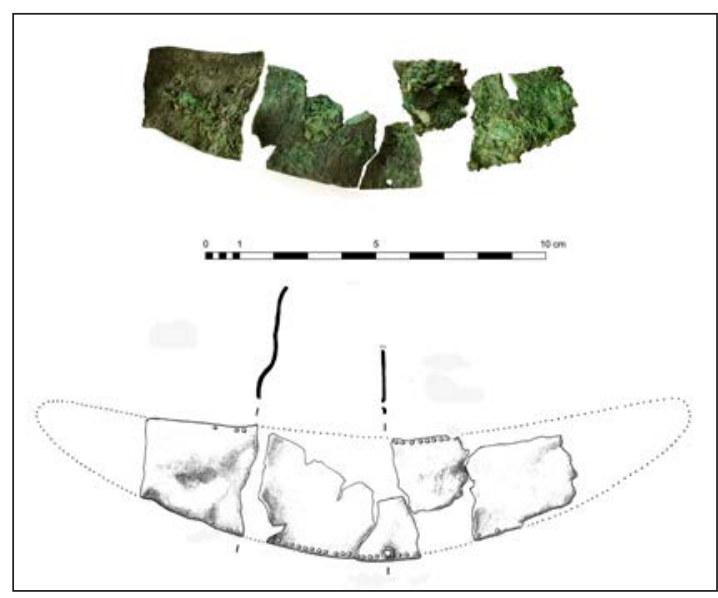

Figura 18. 170.8. Lúnula (Foto Gabinete Trama S. L.).

cinerario, la placa fue plegada sobre sí misma. Tiene $24,5 \mathrm{~cm}$ de longitud y una anchura máxima de $6 \mathrm{~cm}$. Conserva en el borde inferior de la pieza tres pequeñas perforaciones de entre 1,5 y $2 \mathrm{~mm}$ de diámetro, para la sujeción al vestido. Presenta decoración geométrica repujada y troquelada, con una línea de puntos delimitando el contorno de la pieza y, al interior, dos bandas enfrentadas de bastones verticales rematados en botones circulares (Fig. 19). Estos motivos los encontramos formando parte de las decoraciones plásticas de las cerámicas vettonas y en dos cascos celtibéricos procedentes de la necrópolis de Almaluez (Soria), que se fechan en el s. v a. C o a comienzos del s. IV a. C. (Graells et alii 2014: 187, fig. 136-138 y 183). Para ellos, se ha apuntado la posibilidad de que se trate de estilizaciones de figuras antropomorfas

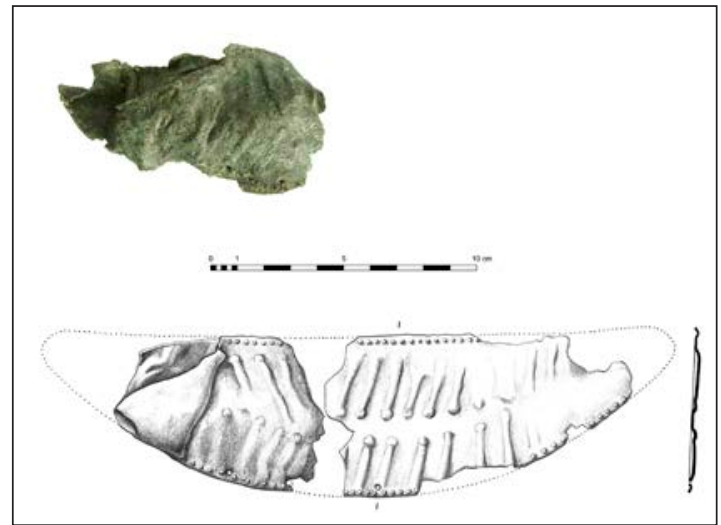

Figura 19. 174.5. Lúnula con decoración geométrica de bastones rematados en botones circulares (Foto Gabinete Trama S. L.).

(Barril 2003: 48, fig. 27-30). También se encuentran entre los elementos que adornan el escudo de la tumba 20 de Alpanseque (Soria), datada entre los s. V y IV a. C. (Cabré Aguiló 1939-1940: lám. IV; Graells et alii 2014: fig. 186) (Fig. 20). En El Castillo se han registrado motivos similares en una copa caliciforme (19.3) recuperada en la e. f. 19.

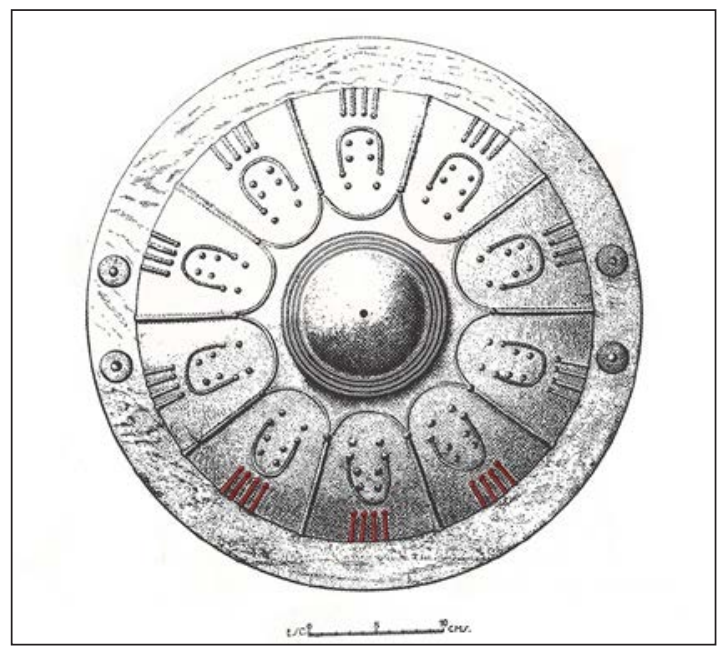

Figura 20. Necrópolis de Alpanseque, Soria. Tumba 20. Bastones verticales rematados en botones circulares decorando un escudo (según Cabré 1939-1940: lám. V; Graells et alii 2014: fig. 186).

Fase III ( $2^{a} 1 / 2$ s. IV - s. III a. C. $)$

En esta etapa se han documentado cuatro lúnulas asociadas a dos enterramientos (e. f. 28 y 149), lo que supone su uso en el 3,27\% de las tumbas clasificadas en este período. Aunque pervive el uso de 
las lúnulas en los rituales funerarios, el porcentaje desciende notablemente respecto a la etapa anterior.

Lúnula 128.16: procede del interior de un túmulo con anillo perimetral de adobes. El ejemplar se encontró fragmentado y deformado, con uno de los pedazos depositado en el interior de la urna. Las labores de consolidación y restauración han permitido reconstruir gran parte de su estructura. En origen tenía un longitud aproximada de $25 \mathrm{~cm}$ y una anchura máxima, en su zona central, de $5,9 \mathrm{~cm}$. Conserva dos pequeñas perforaciones, de entre 1 y $2 \mathrm{~mm}$ de diámetro para la sujeción al vestido, una de ellas situada en uno de los extremos de la lúnula. Presenta decoración geométrica repujada y troquelada, con una línea de puntos delimitando el contorno de la pieza y al interior círculos concéntricos. Pese al deterioro, todavía se distinguen cuatro de esos círculos (Fig. 21).

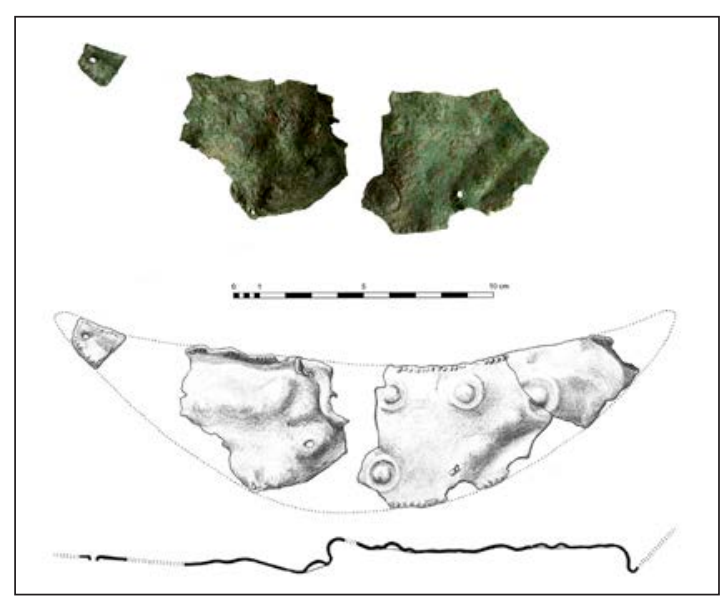

Figura 21. 28.16. Lúnula (Foto Gabinete Trama S. L.).

Lúnulas 149.10: Los tres ejemplares catalogados con este número de inventario fueron hallados en el interior del depósito de cenizas de un enterramiento delimitado por un anillo perimetral de cantos rodados, junto a los recipientes que formaban parte del servicio cerámico y a otros objetos de indumentaria y adorno personal (Fig. 22). A pesar de sufrir las consecuencias del ritual de cremación, son los mejor conservados de todo el conjunto, junto con el ejemplar 152.23. Las tres piezas fueron portadas por un solo individuo y por esta razón, son de distintas dimensiones. La más pequeña se situaba en la parte superior, la más próxima al cuello, tiene una longitud de $24 \mathrm{~cm}$ y una anchura máxima de $6 \mathrm{~cm}$. La segunda se colocaba inmediatamente debajo de la anterior, ocupando una posición central, tiene $31 \mathrm{~cm}$ de longitud y una anchura máxima de $6,5 \mathrm{~cm}$. La tercera se ubicaba en la parte inferior, tiene $35 \mathrm{~cm}$ de longitud y una anchura

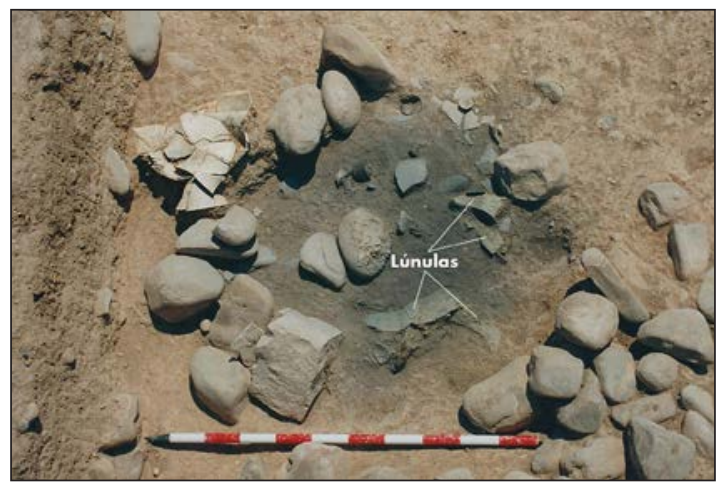

Figura 22. E. F. 149. Identificación de lúnulas (149.10) en el depósito de cenizas (Foto Gabinete Trama S. L.).

máxima de 7,4 cm. Las tres lúnulas presentan idéntica decoración geométrica repujada y troquelada, con una línea de puntos delimitando el contorno exterior y, al interior, círculos concéntricos. Los círculos se agrupan en columnas verticales de tres unidades en la zona central (cuatro filas en el ejemplar de menor longitud, seis en el intermedio y ocho en el de mayor tamaño), que dejan paso en los extremos a columnas de dos unidades y/o a una única unidad de mayor diámetro (Fig. 23). En la sepultura 7 de la cercana necrópolis de La Torraza (Valtierra, Navarra) se recuperó un ejemplar de idéntica factura, que fue clasificado como diadema. Tiene $36 \mathrm{~cm}$ de longitud y $6 \mathrm{~cm}$ de anchura máxima y presenta ocho columnas verticales de tres círculos concéntricos (Maluquer 1953: 261, fig. 5; Castiella 2007: fig. 36) (Fig. 24). Todo apunta, por tanto, a que se trata de piezas que fueron elaboradas en un mismo taller.

\subsection{Tipología}

Las siluetas de las lúnulas de El Castillo, a diferencia de los modelos característicos de la Edad del Bronce, son más abiertas y carecen de remates diferenciados para su sujeción al cuello. En su lugar presentan pequeñas perforaciones en los extremos y a lo largo de todo el borde inferior de las piezas, lo que indica que para su exhibición debían ser previamente cosidas a la vestimenta. Un sistema de fijación que también se registra en el ejemplar procedente de la sepultura 7 de La Torraza (Valtierra, Navarra) (Maluquer 1953: 251-254, fig. 5; Castiella 2007: 226-227, fig. 36). Por este motivo, a pesar del evidente carácter estético de estas lúnulas, son objetos estrechamente vinculados a la indumentaria. Ocupaban el espacio comprendido entre los hombros, el cuello y el pecho y lo habitual es que se utilizara una sola pieza, aunque 


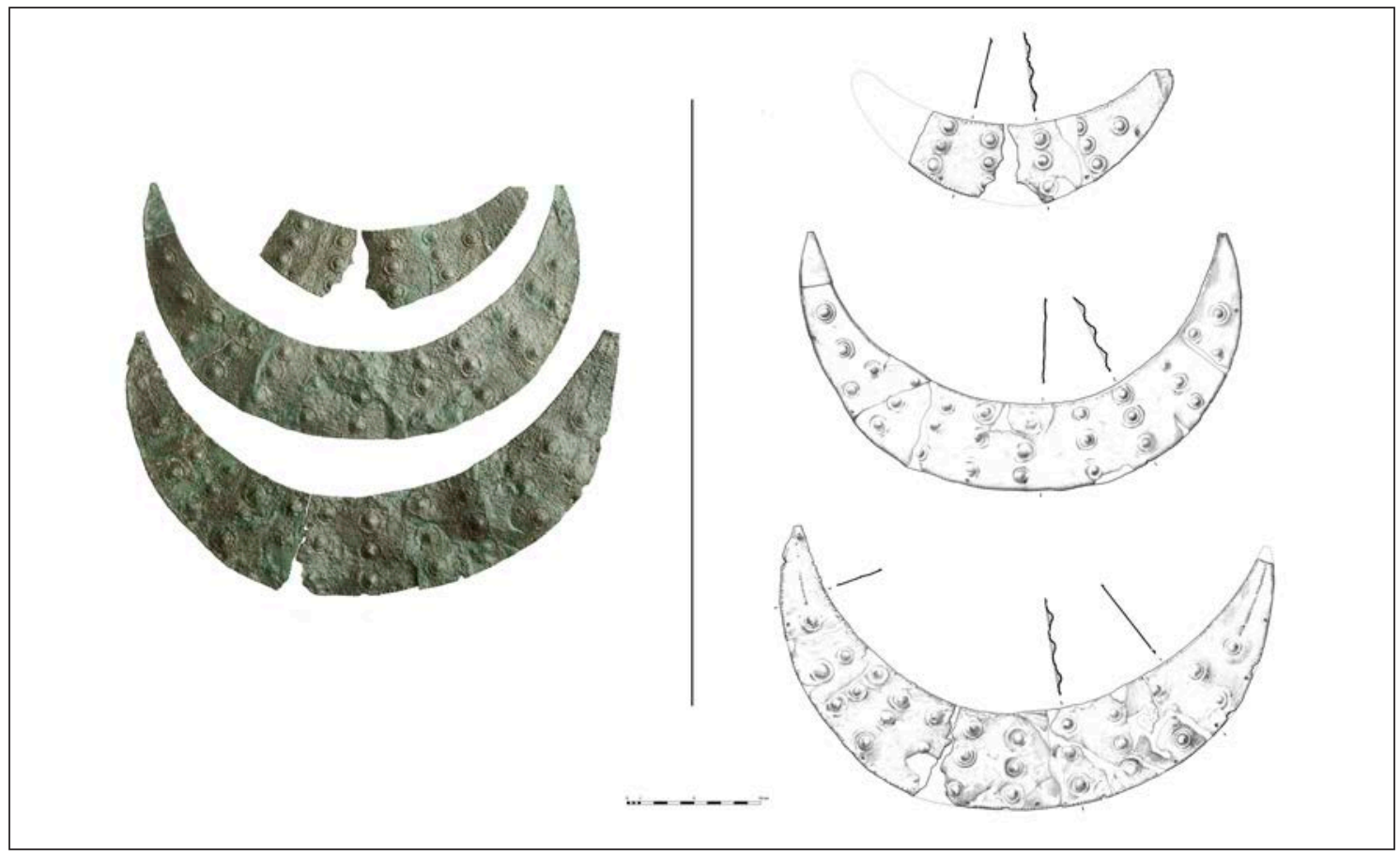

Figura 23. 149.10. Lúnulas con decoración geométrica de círculos concéntricos (Foto Gabinete Trama S. L.).

en casos excepcionales el individuo podía llevar más de una lúnula formando composiciones complejas, como sucede con los tres ejemplares hallados en la e. f. 149 o con las dos lúnulas con decoración figurada depositadas en el interior de la e. f. 152. Esta disposición también se observa en representaciones iconográficas peninsulares de la Edad del Bronce y principios de la Edad del Hierro, como sucede en

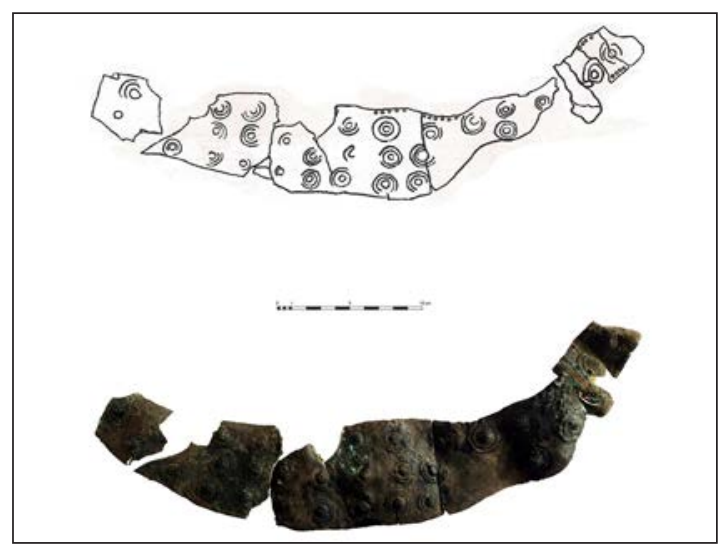

Figura 24. Necrópolis de La Torraza, Valtierra, Navarra. Sepultura 7. Lúnula similar a los ejemplares de la e.f. 149 de El Castillo (Maluquer 1953: fig. 7; Castiella 2007: fig. 36) (Foto Sección de Arqueología del Servicio de Patrimonio Histórico del Gobierno de Navarra). algunas estatuas-menhir y en estelas diademadas (Santos 2009: fig. 1 y 6).

$\mathrm{El}$ análisis de las piezas, en función de su morfología, ha permitido individualizar dos tipos diferentes de lúnulas (Figs. 25 y 26):

Tipo 1: en este grupo se incluyen los ejemplares más estrechos, con anchuras máximas de entre 2-3 $\mathrm{cm}$, y que presentan contornos algo más cerrados, en forma de "U", con una menor distancia entre los extremos. La decoración se limita a una sencilla línea de puntos repujados que delimita el perímetro de la pieza.

Este modelo está representado por las dos lúnulas (46.6 y 123.4) halladas en enterramientos fechados en la Fase $I$ ( $2^{\mathrm{a}} 1 / 2 \mathrm{~s}$. VI - principios s. v a. C. $) \mathrm{de}$ El Castillo.

Tipo 2: en este grupo se incluyen ejemplares con contornos más abiertos y con anchuras máximas de entre 3 y $6 \mathrm{~cm}$, con casos excepciones que pueden llegar a alcanzar los 7-8 cm, como es el caso de uno de los ejemplares figurados de la e. f. 152.

A este modelo corresponden las catorce lúnulas identificadas en túmulos de la Fase II ( $2^{\mathrm{a}} 1 / 2 \mathrm{~s}$. v $-1^{\mathrm{a}}$ $1 / 2$ s. IV a. C.) y de la Fase III ( $2^{\mathrm{a}} 1 / 2$ s. IV - s. III a. C.). A partir de la decoración y de su distribución en las lúnulas se han establecido tres variantes:

- Variante A: al igual que en las piezas del tipo 1, una sencilla línea de puntos repujados delimita 


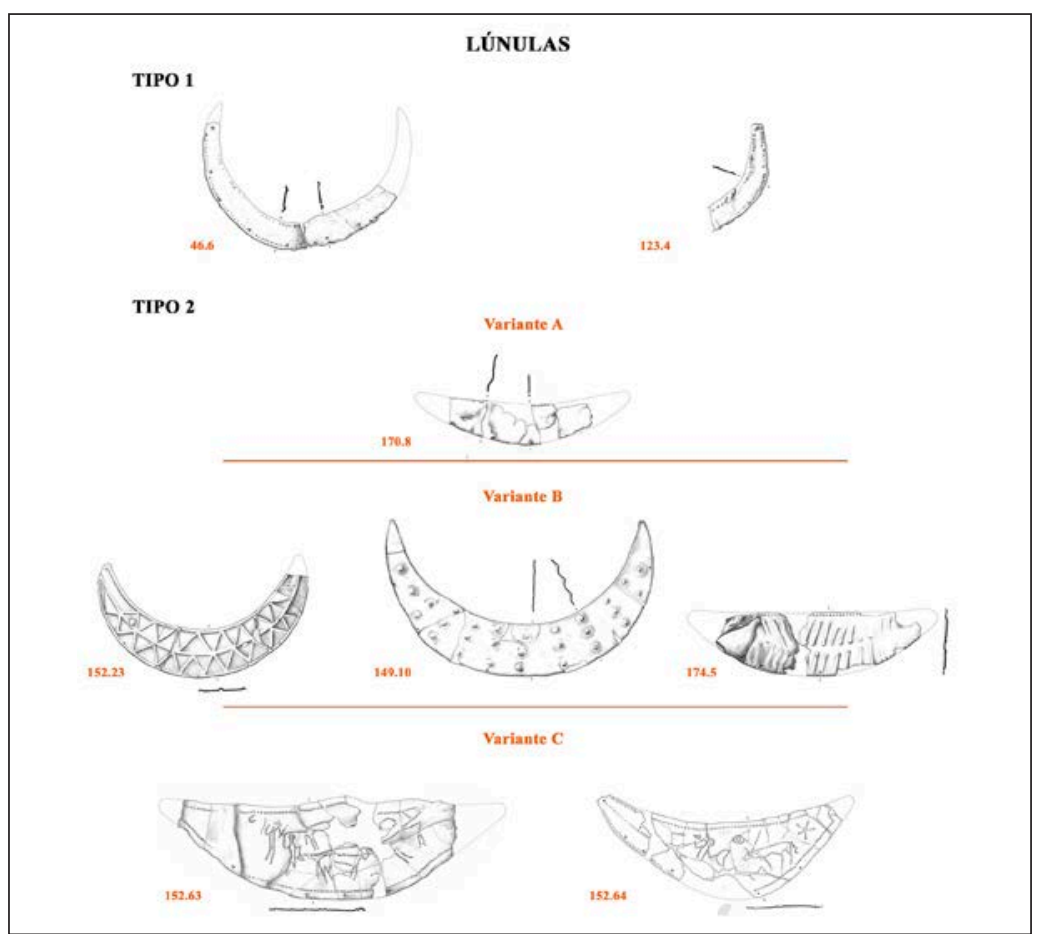

Figura 25. Tipología de las lúnulas identificadas en la necrópolis de El Castillo.

el perímetro de la lúnula. El único ejemplar que responde a este modelo es el 170.8.

- Variante B: la decoración geométrica se extiende por toda la superficie. Al margen de una línea troquelada en resalte o de puntos repujados marcando el contorno de la pieza, presenta en el interior decoración geométrica. Los motivos son muy variados, los más repetidos son los círculos concéntricos, que se documentan en siete lúnulas $(28.16,152.65,154.22,155.6$ y los tres ejem- plares del 149.10). También se han identificado triángulos (152.23), retículas de rombos (152.40) y bastones verticales rematados en botones circulares (174.5).

- Variante C: presentan decoración figurada mediante técnica de repujado, formando escenas complejas. Los dos únicos ejemplares que responden a este modelo se localizaron en el interior de la urna funeraria del enterramiento 152 (152.63 y 152.64).

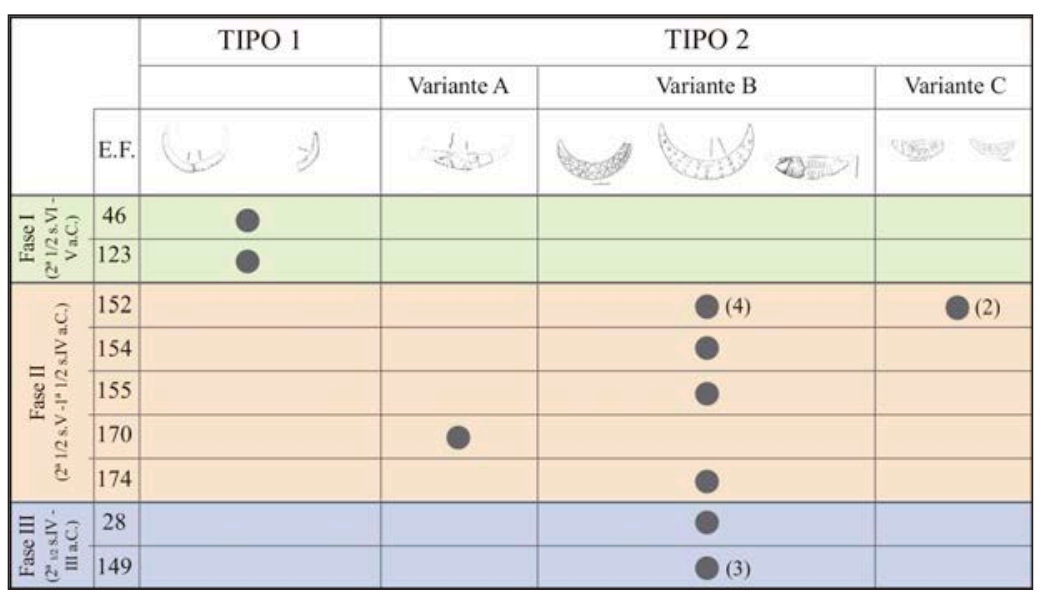

Figura 26. Correlación entre las estructuras funerarias y las lúnulas de la necrópolis de El Castillo. 


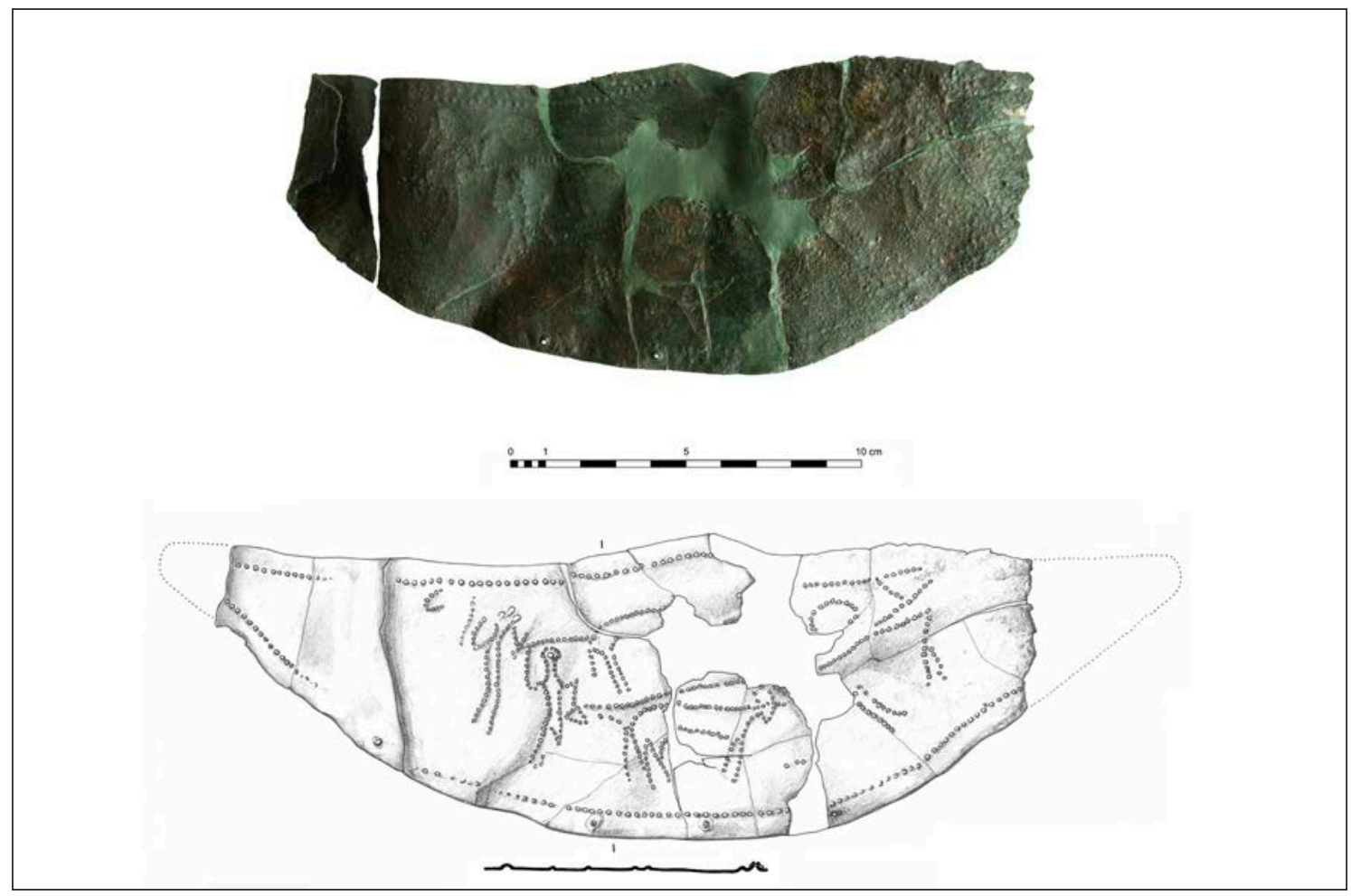

Figura 27. 152.63. Lúnula con decoración figurada. Escena de arado (Foto Gabinete Trama S. L.).

\subsection{ESTUdio ICONOGRÁFICO DE LAS LÚNULAS CON DECORACIÓN FIGURADA}

Las lúnulas 152.63 y 152.64 , como se ha indicado anteriormente, son las únicas de todo el conjunto que presentan decoración figurada. Fueron depositadas en el interior de la urna cineraria del enterramiento $152 \mathrm{y}$, como se deduce tanto de la disparidad de sus tamaños como del programa iconográfico, fueron diseñadas para ser exhibidas juntas por un mismo individuo.

Lúnula 152.63: el proceso de identificación resultó muy complejo por el acusado deterioro que presentaba la pieza, como consecuencia de haber quedado expuesta al fuego de la cremación. Pese a ello, se ha identificado una escena de temática agrícola (Fig. 27). En primer término se sitúa una figura humana esquemática de pie, con el ojo destacado por un círculo. Lleva el brazo derecho alzado en actitud de sostener una vara o fusta y, con el brazo izquierdo, maneja un arado sujetándolo por la esteva, que llega hasta la reja (Fig. 28). Desde esta parte, en sentido horizontal, una línea de puntos representa al timón de cama curva, el cual estaba uncido a una pareja de cuadrúpedos, posiblemente de bueyes. En la parte inferior de la lúnula se sitúa la figura de uno de los animales de tiro. La posición del segundo coincide con un fragmento no conservado y únicamente se observan dos trazos diagonales paralelos que podrían corresponder a los cuartos delanteros. En segundo término, en la parte superior de la pieza, la escena se repite, aunque se aprecia con menor nitidez. Un segundo personaje, también de pie, guía otra yunta de animales de tiro.

La iconografía del labrador arando la tierra se asocia a ritos indoeuropeos relacionados con la fertilidad de la naturaleza y con la renovación (Dumèzil 1954; Lucas 1990: 293). Precedentes a este tipo de

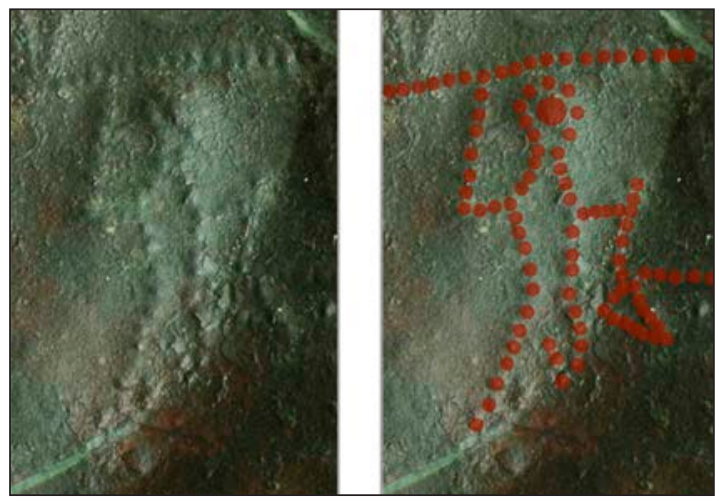

Figura 28. 152.63. Detalle del personaje que sostiene el arado (Foto Gabinete Trama S. L.). 


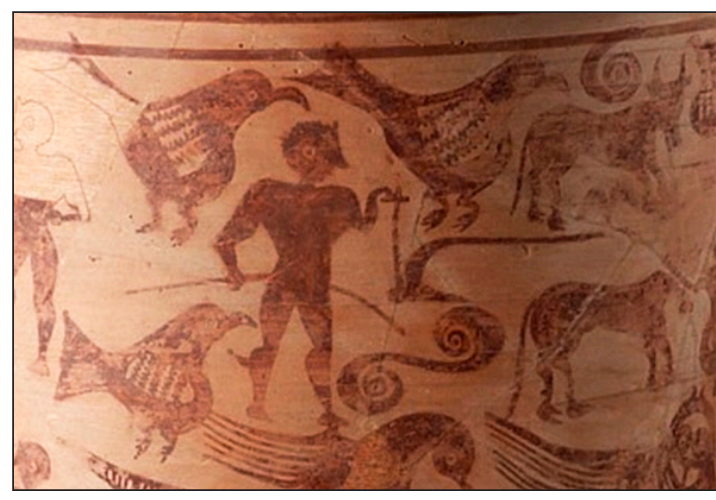

Figura 29. Kalathos del arado de Cabezo de la Guardia, Alcorisa, Teruel (Mata 1998: 94).

representaciones se pueden hallar tanto en la cerámica griega, como en terracotas y bronces etruscos e itálicos. Quizá uno de los ejemplos más significativos sea el de la sítula de la tumba 68 de la necrópolis de La Certosa (Bologna), fechada en el primer cuarto del s. v a. C. (Bosi et alii 2001: fig. 2; Lucas 1990: fig. 7a). En la Península la mayoría de las representaciones se concentran en el territorio ibérico. Las más destacadas se hallan en el bajo Aragón y corresponden a las escenas pintadas en sendos kalathoi procedentes de los poblados del Cabezo de Alcalá (Azaila, Teruel) (Cabré Aguiló 1944: 65-67, fig. 46, lám. XXXII) y del Cabezo de la Guardia (Alcorisa, Teruel) (Atrián y Martínez González 1976: 74, fig. 19, lám. XV-
XVIII) (Fig. 29), que están fechados entre finales del s. II y principios del s. I a. C. Otros testimonios los encontramos en el poblado del Castellet de Banyoles (Tivissa, Tarragona), donde se recuperó un bronce votivo de una yunta de bueyes (Serra-Ráfols 1941: 25, lám. IV); en La Bastida de les Alcusses (Moixent, Valencia), donde se documentó un buey de bronce y fragmentos de un yugo y un timón (Bonet et alii 2011: 159, fig. 18 y 30) o en el arado votivo de hierro de Covalta (Albaida, Valencia) (Plá 1951-1952: 12-27, lám. I-II).

Lúnula 152.64: la escena representada es de temática cinegética (caza de ciervo), obtenida mediante técnica de repujado. Al igual que en el caso anterior, el proceso de identificación de los motivos resultó complejo. Aparecen dos figuras esquemáticas enfrentadas. Una figura humana, en primer término, que se representa de pie y con el ojo destacado por un círculo. Sostiene con el brazo izquierdo un escudo circular cóncavo visto de perfil, mientras que con el derecho parece empuñar una lanza. Del animal se aprecian con claridad los cuartos traseros, junto a los que se observa una línea quebrada, y el lomo. Los puntos del repujado de los cuartos delanteros y la cabeza no se distinguen con tanta nitidez. La escena está presidida por símbolos astrales situados en la parte superior de la pieza, una luna y un sol, ocupando el centro y uno de los extremos. El contorno de la lúnula queda delimitado por una línea de puntos repujados (Fig. 30).

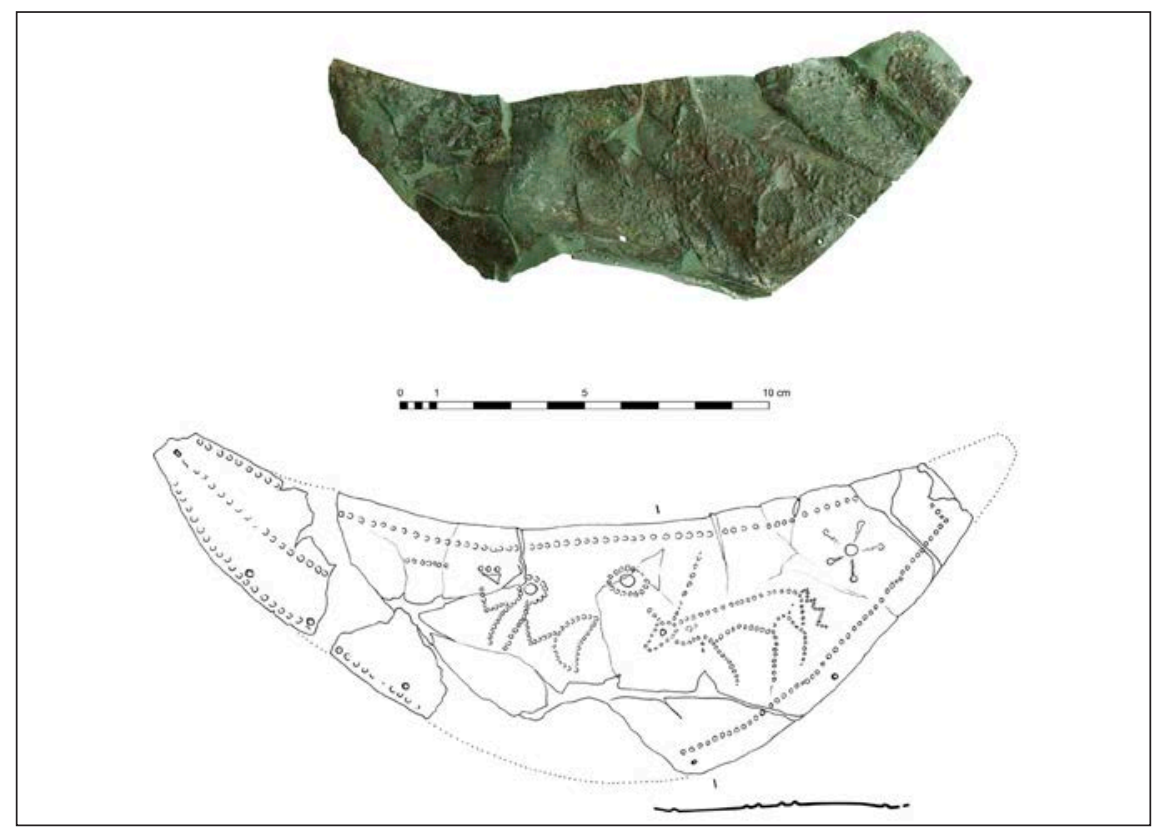

Figura 30. 152.64. Lúnula con decoración figurada. Escena de caza (Foto Gabinete Trama S. L.). 
Los ciervos, junto a las aves, son los motivos zoomorfos mejor representados en el valle del Ebro. Existen referentes en soportes de cerámica, bronce e incluso en grabados y pintura sobre piedra. Imágenes de venados se han documentado en poblados como Cabezo del Lugar (Azaila, Teruel), Cabezo Moleón (Caspe, Zaragoza), El Morredón (Fréscano, Zaragoza) o La Coronilla (Lardero, La Rioja) y en santuarios rupestres como el de Peñalba de Villastar (Teruel) (Díaz Ariño et alii 2011: 113-115, fig. 4,5 y 8).

La iconografía del ciervo en la cultura céltica y celtibérica encierra connotaciones de carácter religioso y funerario. Los cuernos de los cérvidos eran considerados como símbolos de fertilidad y de inmortalidad (Sopeña 1987: 49 y 124; Marco 1989: 119 122). Unas atribuciones que subyacen en las placas ornamentales con figuras de ciervos que aparecen en las necrópolis celtibéricas de Carratiermes (Montejo de Tiermes, Soria) (Argente et alii 2001: 114-115), Quintanas de Gormaz (Soria) (Lorrio y Sánchez de Prado 2007: 520, fig. 12.5) o Navafría (Clares, Guadalajara) (Lorrio y Sánchez de Prado 2009: 520, fig. II-2), en ámbitos fechados entre los s. VI - IV a. C. $\mathrm{y}$ que, de igual forma, pueden aplicarse al referente más cercano localizado en el valle medio del Ebro, la figurita de bronce procedente de la necrópolis de La Torraza (Valtierra, Navarra) (Maluquer 1953: 264265; Castiella 2007: fig. 28) y también al colgante de bronce del poblado de Cabezo Morrudo (Fuentes de Ebro, Zaragoza) (Marco y Royo 2012: 313, fig. 7.1).

Las escenas de caza del ciervo son más habituales en el territorio ibérico. No deben interpretarse como la plasmación de una mera actividad cinegética, sino como el escenario de una acción heroica, el personaje o los personajes representados demuestran su valía enfrentándose a este animal (Chapa 1985: 92). Sirva como ejemplo la escena del Vaso Cazurro (Barcelona), donde dos varones con jabalinas persiguen a la carrera a unos ciervos (Fig. 31). Dicha cacería ha sido interpretada como un ritual iniciático de adolescentes (Chapa y Olmos 2004: 59-60, fig. 13). Una composición que se repite a caballo en el vaso de los guerreros de La Serreta (Alcoi, Alicante) (Olmos y Grau 2005: 92-94, lám. VII), o en el vaso de la caza de los ciervos del Tossal de Sant Miquel (Lliria, Valencia) (Bonet et alii 1995: 174, fig. 84).

El escudo y la lanza aparecen constantemente en la iconografía celtíbera e ibérica, tanto en escenas de caza como en combates entre guerreros. La combinación de estas dos armas también se reproduce con relativa frecuencia, como se documenta en la escultura del jinete en pie frente al enemigo vencido del herôn de Obulco (Porcuna, Jaén) (Negueruela 1990: 171), en el vaso de los guerreros del Tossal de Sant Miquel

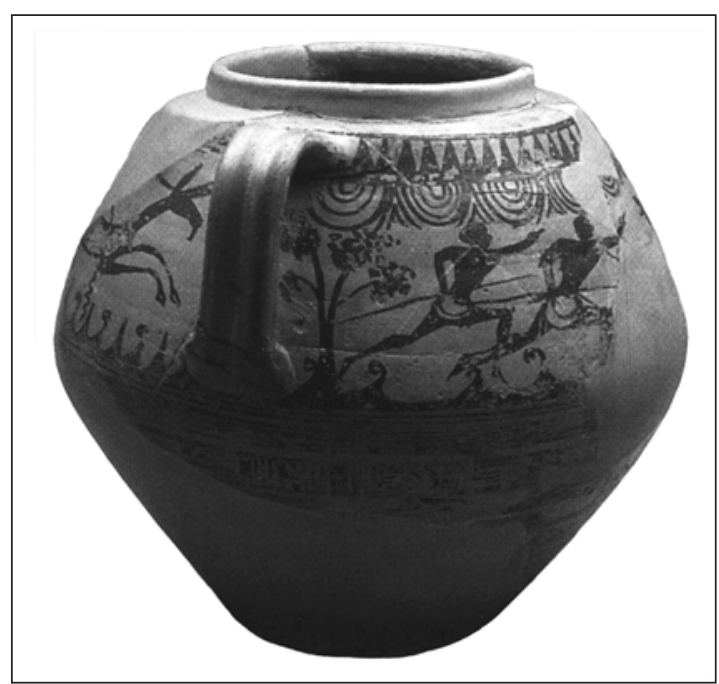

Figura 31. Vaso Cazurro (Barcelona). Escena de caza de un ciervo (Chapa y Olmos 2004: fig. 13).

(Lliria, Valencia) (Bonet et alii 1995: lám. XIX), en el kalathos de El Castelillo (Alloza, Teruel) o en el vaso de los guerreros de Numancia (Garray, Soria) (Romero 1999). La representación de escudos circulares cóncavos vistos de perfil se registra tanto en el ámbito ibérico como en el celtibérico, donde las referencias más ilustrativas las hallamos en el broche de cinturón de la necrópolis vettona de La Osera (Chamartín de la Sierra, Ávila) (Quesada 1997: fig. 304), en el pomo del puñal de la sepultura 32 de la necrópolis vaccea de Las Ruedas (Padilla de Duero, Valladolid) (Sanz Mínguez 1997: 86) y sobre todo en las cerámicas del Tossal de Sant Miquel (Lliria, Valencia), en vasijas pintadas como el vaso de la batalla naval o el vaso de la doma (Bonet et alii 1995: fig. 27 y 61, lám. XX y $\mathrm{XXV}$ ). Esta perspectiva también se advierte en los escudos de algunos de los guerreros representados en las cerámicas numantinas (Schulten 1931: lám. XXVI.5) y en el del guerrero celtibérico pintado del abrigo del Barranco de los Frailes (Mosqueruela, Teruel) (Lorrio y Royo 2013: fig. 5). Los escudos vistos de perfil, en ocasiones, han sido erróneamente interpretados como arcos, por el parecido formal que guardan con estas armas. En la lúnula de El Castillo la posición del brazo derecho, alzado y con ademán de empuñar una lanza, descarta cualquier posibilidad de que el objeto reproducido sea un arco. Además, como bien señala Quesada, sería absurdo situar un arco sin tensar en un contexto de caza, en el que debiera figurar con la cuerda dispuesta para el disparo y en las manos del cazador (Quesada 1989: 182).

La presencia de dobles espirales y de líneas quebradas en forma de series de eses junto a la grupa de 
los animales ha sido interpretada, en la iconografía ibérica y celtibérica, como expresión de movimiento. Un buen ejemplo es la cierva herida del Vaso de los Guerreros de La Serreta (Alcoi, Alicante) (Olmos y Grau 2005: 93; Pastor 2010: 473). En contextos de caza, este tipo de trazos se utilizan para señalar las secuencias onomatopéyicas de los movimientos de los cazadores y de las presas (Pastor 2010: 481).

El ciervo, por su condición de animal psicopompo e intermediario, también facilita las relaciones con el mundo celeste. En este caso, la esfera celeste está representada por un sol y una estrella, símbolos astrales relacionados con el paso del día a la noche, una temática muy vinculada a contextos funerarios y a rituales de tránsito al Más Allá.

Las escenas reproducidas en las lúnulas con decoración figurada de la e. f. 152 forman parte de la narrativa iconográfica de culto al antepasado esencial, al "Héroe Fundador" de la estirpe. Los mitos vinculados a Teutates o al "Heroe Fundador" estuvieron ampliamente extendidos entre las élites celtibéricas e ibéricas y constituyeron la base ideológica de las sociedades protohistóricas de Europa Occidental. Las principales gestas de este héroe mítico, siguiendo las tesis defendidas por autores como Almagro-Gorbea y Lorrio (2011: 63-68), pueden deducirse y reconstruirse a través de la mitología comparada, ya que parten de un fondo común indoeuropeo al que se suman influencias greco-orientales. La representación del labrador arando la tierra se relaciona con el episodio en el que el héroe, ya en su condición de rex, enseña a manejar el arado. Con él funda la ciudad, mediante el ritual del "surco primordial o primigenio" (Olmos 2000: 71; Moneo 2003: 419; Almagro-Gorbea y Lorrio 2011: 68), una acción que también se repite en los kalathoi de Alcorisa y Azaila. La presencia en la lúnula de El Castillo de un segundo labrador debe asociarse al mito indoeuropeo de los "gemelos divinos", los dos primeros hombres del inicio del tiempo nacidos en último término del fuego (Pérez Vilatela 2009: 7382; Almagro-Gorbea y Lorrio 2010: 164-165). Un mito que alcanzó una amplísima difusión y que en Grecia está ilustrado por personajes como Cástor y Pólux y en Roma por Rómulo y Remo. En Hispania se ha propuesto esta interpretación para los gemelos que aparecen situados en los brazos de la diosa, en la terracota del santuario de La Serreta (Alcoi, Alicante) (Almagro-Gorbea y Lorrio 2011: 66, fig. 22.B). Por otro lado, las hazañas individuales de caza y de lucha formaban parte de las pruebas ordálicas que el héroe debía superar durante su etapa de exposición y alejamiento iniciático (Almagro-Gorbea y Lorrio 2011: 66). En este contexto iniciático sitúan diversos autores las escenas procedentes del hêron ibérico de
Obulco (Porcuna, Jaén) (Chapa y Olmos 2004: 4650, fig. 4 y 5; Almagro-Gorbea y Lorrio 2011: 66, fig. 22.A y 22.B).

\subsection{FunCIONALIDAD, ASOCIACIONES Y CRONOLOGÍA}

Las lúnulas, por su escaso número, pueden considerarse como elementos excepcionales en los yacimientos arqueológicos del territorio peninsular. Las piezas recuperadas en la necrópolis de El Castillo constituyen el conjunto mejor contextualizado y el que presenta una cifra más elevada de ejemplares.

El origen de las lúnulas se remonta hasta el Neolítico. Sobre la génesis de estos objetos existen dos corrientes diferenciadas: los que abogan por un origen oriental y los que respaldan un origen occidental. Los defensores de la primera tesis señalan que, en civilizaciones como la egipcia y la hitita, existen distintos elementos de adorno con formas de crecientes lunares que pudieron ser el germen de las lúnulas. En Egipto, ya en el Imperio Antiguo, se utilizaron diversos collares ceremoniales, como el Menat o el Aegis, con formas de media luna. El Aegis podía ser macizo y elaborarse en metales como el oro y el bronce. Asimismo, para los hititas los collares en forma de media luna tuvieron una especial trascendencia desde finales del III milenio a. C. Por su parte, los que apoyan la segunda teoría argumentan que los testimonios de lúnulas en el área portuguesa puede retrotraerse hasta finales del IV milenio a. C. Es el caso de las lúnulas que aparecen representadas en las estatuas-menhir de Almendres (Evora) y de Portela de Mogos (Evora), fechadas en el Neolítico Final/ Calcolítico (Gomes 1997: 258-269, fig. 4, 7, 8 y 9; Gomes 2011: fig. 3, 4 y 5) (Fig. 32). Pertenecientes a esta misma etapa, también se han hallado placas de

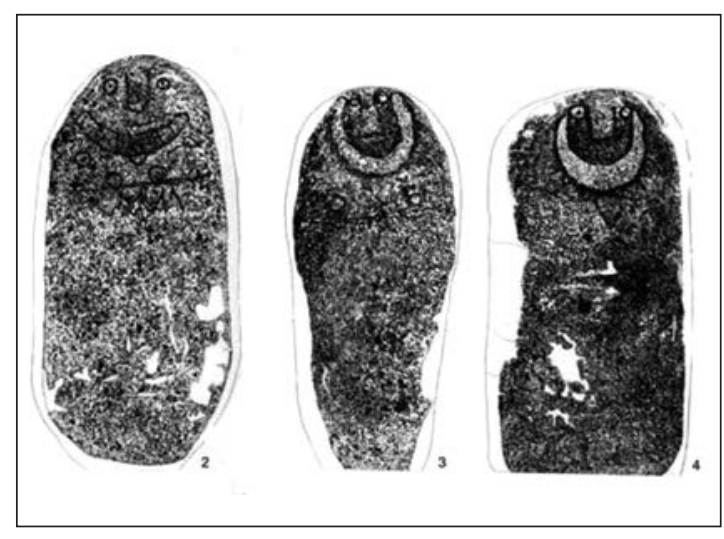

Figura 32. Estatuas-menhir de Almendres, Evora (Gomes 1997: fig. 4). 


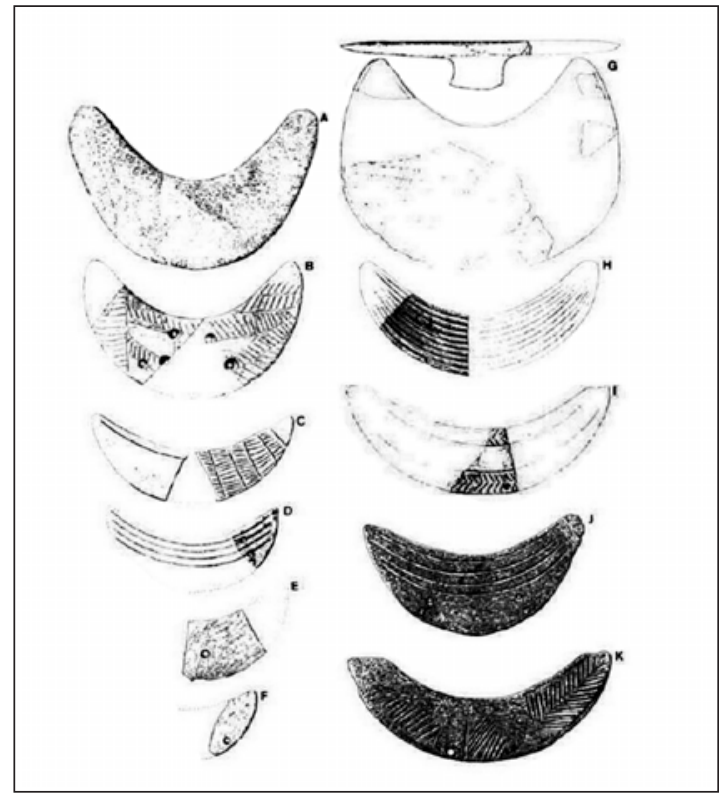

Figura 33. Lúnulas de piedra caliza del área de Lisboa (Gomes 2011: fig. 8).

piedra caliza con forma de lúnula y con decoraciones geométricas incisas en el área de Lisboa (Gomes 2011: fig. 8) (Fig. 33). Algunas de ellas proceden de ámbitos funerarios, como el ejemplar de la necrópolis de Baútas (Mina, Amadora) (Gonçalves et alii 2004: 129). Estos ejemplares guardan una notable semejanza con las piezas de arcilla que se documentan en Europa Central durante el Bronce Final y comienzos de la Edad del Hierro, conocidas como "Mondhörner".

La etapa de máxima difusión de las lúnulas en el extremo occidental de Europa coincide con el final del Calcolítico y con el Bronce Antiguo. A este período corresponde la mayoría de los ejemplares fabricados en oro, con el foco principal centrado en Irlanda y Gran Bretaña. En la Península Ibérica, las piezas registradas se concentran en el ámbito territorial de Galicia y el norte de Portugal. En este contexto se sitúan las lúnulas de Cerdido (Sarlegui 1894: 31, 32 y 283; García Vuelta y Armada 2003: 120-121, fig. 4), Allariz (Orense) (Barros 1875: 283) y Cabeceiras de Bastos (Braga, Minho) (Comendador 1998: 49 y 106, catálogo 48).

Durante el Bronce Final se observa un descenso acusado en el número de lúnulas, que se atribuye al auge de nuevos elementos de adorno como los torques. Pese a ello, en la Península Ibérica esta circunstancia no supuso la desaparición de las lúnulas, como atestiguan las representaciones iconográficas y el registro arqueológico. Un ejemplo de esta realidad lo constituyen los objetos de estas características que se documentan en las estelas diademadas, en conjuntos como el de Hernán Pérez (Cáceres) (Almagro Basch 1972: 86-91; Santos 2009: fig. 1.1-4) y en estelas aisladas como las de Torrejón El Rubio V (Cáceres) (Santos 2009: fig.5) o Granja Toniñuelo (Jerez de los Caballeros, Badajoz) (Bueno y Balbín 1997: fig. 23; Santos 2009: fig. 1.9), entre otras (Fig. 34). Las líneas actuales de investigación plantean una cronología situada entre el Bronce Final y comienzos de la Edad del Hierro (Santos 2009) y las vinculan al mundo funerario (Celestino 2001: 259-260).

Las referencias a lúnulas no abundan a lo largo de la Edad del Hierro, aunque sí son suficientes para constatar una pervivencia y para advertir una evolución, tanto en los modelos como en las técnicas y los materiales. Los modelos cerrados y con remates diferenciados para su sujeción al cuello, característicos de la Edad del Bronce, comenzaron a convivir con otros más abiertos y que, en ocasiones, se colocaban entre los hombros, el cuello y el pecho, cosidos a la vestimenta. Las decoraciones geométricas sencillas, realizadas mediante técnicas como la incisión o el puntillado, fueron dando paso a composiciones más complejas para las que recurrieron a técnicas como el

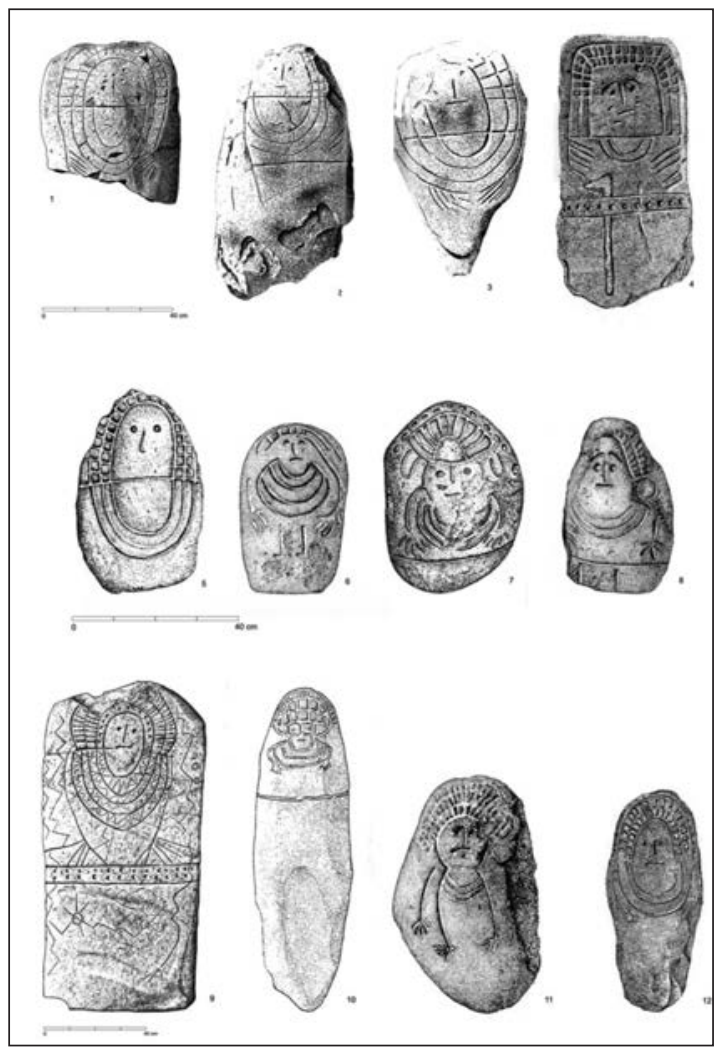

Figura 34. Estelas diademadas (Santos 2009: fig. 1). 
repujado o el troquelado. Por último, en este período también se produjo un descenso muy significativo de las piezas de oro, así como la irrupción de piezas realizadas en plata y bronce. Un ejemplo temprano, fechado en el s. viII a. C., es la lúnula de bronce de procedencia caucásica del Museo de Pyatigorsk, que presenta decoración de círculos concéntricos troquelados similares a los registrados en las necrópolis de La Torraza (Valtierra, Navarra) y El Castillo.

En la Península Ibérica, en esta etapa inicial de la Protohistoria, al margen de la posible perduración de las estelas diademadas, apenas contamos con referencias. Una de las más singulares es el casco de plata con decoración repujada de Caudete de las Fuentes (Valencia) (Graells y Lorrio 2013: 158, fig. 6), atribuido erróneamente a las Cuevas de Vinromá (Castellón) (Maluquer 1970: 98, fig. 4) (Fig. 35). Atendiendo a su estructura, se ha relacionado con el tipo Vilanova II, lo que le otorga una cronología situada hacia el s. VIII a. C. (Almagro-Gorbea 1977: 122). Esta pieza presenta decoración geométrica. En los laterales se sitúan sendos motivos con forma de cuarto lunar aunque, atendiendo a la naturaleza del objeto, podría responder a la representación de cuernos. Elementos que, en ocasiones, se añadían a los cascos para dar una imagen más feroz del guerrero. En la Península Ibérica, modelos con cuernos aparecen representados desde el Bronce Final, en las estelas del Suroeste (Quesada 1997: 551).

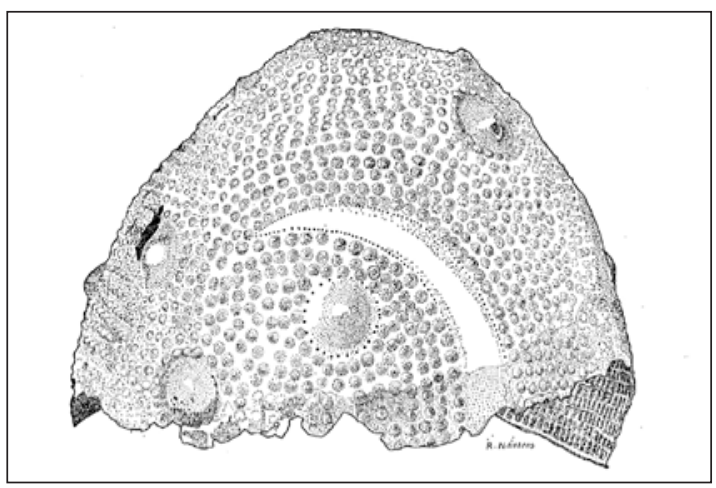

Figura 35. Casco de plata con decoración repujada de Caudete de las Fuentes, Valencia (Maluquer 1970: fig. 4).

A partir del s. vi a. C. comenzaron a documentarse lúnulas con decoración figurada formando escenas complejas. Es el caso de la pieza de bronce hallada en el Santuario de Hera en Samos, en la que se representa el mito de la victoria de Heracles sobre Gerión (Corzo 2004: 39). En la Península, en la necrópolis de La Tosseta (Guiamets, Tarragona), se recuperó un ejemplar fechado hacia el s. VII a. C. que fue deno- minado como "torques plano" y que estaba decorado con series equidistantes de tres líneas transversales en relieve (Vilaseca 1956; Ruiz Zapatero 1985: 171, fig. 48.C). En contextos del s. vi a. C., se clasificó como posible navaja un fragmento de bronce con forma de lúnula depositado en el sepulcro 6 de la necrópolis de Can Bech de Baix (Agullana, Gerona) (Palol 1943: 264, fig. 3; Almagro-Gorbea 1977, fig. 12). En el ajuar de esta misma tumba se recuperó un pendiente con forma de creciente lunar. Una asociación que también se registra en la e. f. 152 de El Castillo. En el interior de la urna, además de las lúnulas, fueron depositados distintos objetos metálicos de indumentaria y adorno, entre ellos dos arracadas de oro de parecida estructura (152.25). Los pendientes con morfología de creciente lunar son objetos que alcanzaron una amplia difusión y que formaron parte de la orfebrería céltica, celtibérica e ibérica hasta la llegada de la cultura romana. Piezas con forma de lúnula también se registran en la orfebrería ebusitana, como es el caso de la lámina de oro depositada en el Museo Arqueológico Nacional (San Nicolás 1986: 69 y 85, fig. 23).

Las referencias más próximas a El Castillo proceden de dos necrópolis del valle medio del Ebro, fechadas entre los s. VI y III a. C. En la sepultura 7 de La Torraza (Valtierra, Navarra), en el interior del recipiente cerámico utilizado como urna, se localizó una lúnula con una composición decorativa idéntica a las halladas en la e. f. 149 de El Castillo (Maluquer 1953: 261-262, fig. 5) (Fig. 24). Asimismo, en La Atalaya (Cortes, Navarra) se menciona la existencia de un elevado número de pequeños fragmentos de placas decoradas que, en algunos casos, se adelgazan en los extremos y que fueron relacionadas con la existencia de piezas similares a la recuperada en la tumba 7 de La Torraza (Maluquer y Vázquez de Parga 1956: 416-417). Al otro lado de los Pirineos, en la necrópolis de Avezac Prat (Bagnères-de-Bigorre, Midi) también se documenta un ejemplar de bronce, con decoración de círculos concéntricos (Pilloy 1899: Pl. VII) (Fig. 36).

Por último, en los siglos que precedieron a la llegada de la cultura romana, también se registran evidencias del uso de lúnulas. En el ámbito ibérico, resulta muy significativa su probable presencia en algunas representaciones femeninas halladas en ámbitos sacros y funerarios, en contextos datados en los s. III - II a. C. Esta circunstancia se observa en un exvoto femenino de terracota del santuario ibérico de La Serreta (Alcoi, Alicante) (Juan i Moltó 1987 1988; Aura y Segura 2000: 220) o en las llamadas "damitas" del monumento funerario de la necrópolis del Corral de Saus (Moixent, Valencia), aunque en este último caso también podría tratarse de torques 


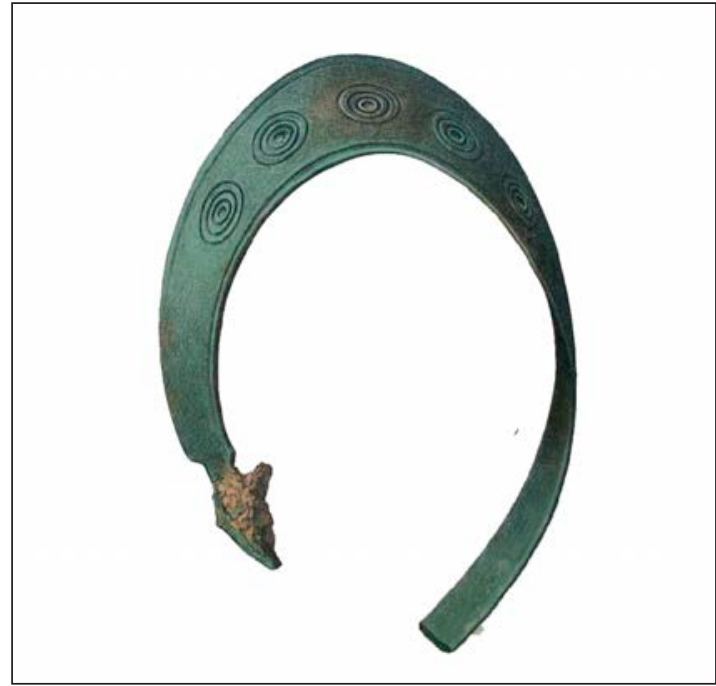

Figura 36. Necrópolis de Avezac Prat, Bagnères-de-Bigorre, Midi. Lúnula. (Pilloy 1899: pl. VII).

(Fletcher 1977: fig. 3, 8 y 9; Izquierdo 1998-1999: fig. 3 y 5, lám. I y II). A la información que aporta la iconografía, se une el hallazgo de ejemplares tan vistosos como la lúnula de plata del tesoro de Chão de Lamas (Miranda do Corvo, Coimbra) (Fig. 37), la lúnula de oro de Viseu (Beira Alta) (Silva 1986: 253), la lúnula de oro y las tres de plata del tesoro de Pragança (Cadaval, Lisboa) (Raddatz 1969: lám. 85-87) o el ejemplar de bronce de Llyn Cerrig Bach (Anglesey, Gales) (Macdonald 2007). Junto a ellos, también se han registrado otro tipo de piezas de orfebrería de menor tamaño pero con la misma mor-

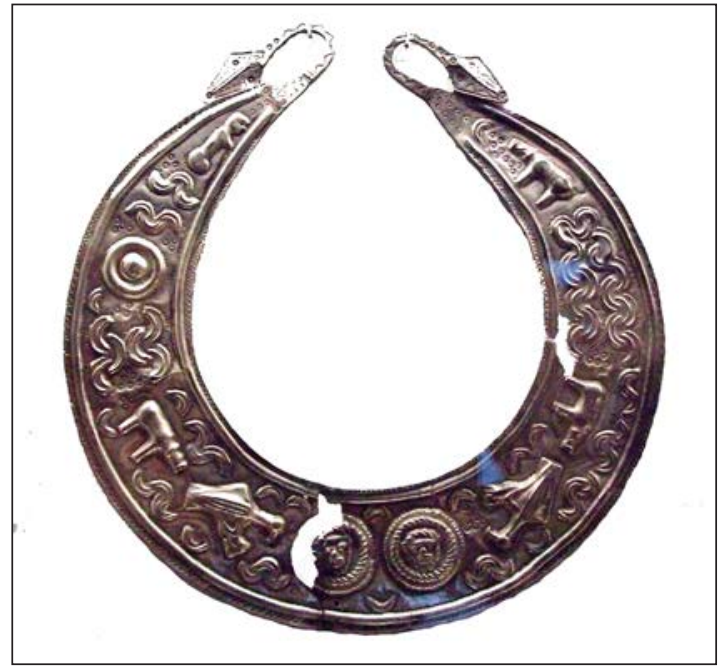

Figura 37. Castro de Chão de Lamas, Miranda do Corvo, Coimbra. Lúnula de plata con decoración figurada (MAN-28589). fología, como es el caso de los doce pendientes de plata del tesoro de Salvacañete (Cuenca) (Arévalo et alii 1998: 259, fig. 3 y 4).

Las lúnulas, al margen de las connotaciones simbólico-religiosas y apotropaicas que puedan derivarse tanto de su morfología como de los motivos representados, tenían una función estética. Los ejemplares de El Castillo fueron diseñados para su colocación a la altura de los hombros de sus propietarios, fijados a la vestimenta. Para este fin disponían de pequeñas perforaciones en el borde inferior y en los extremos. Esta disposición, que dejaba libre el cuello, permitía lucir las lúnulas y combinarlas con collares. En siete de las nueve tumbas en la que se recuperaron lúnulas, también se catalogaron cuentas de collar (e. f. $28,46,149,152,154,170$ y 174), en su mayoría de bronce y en un número elevado de unidades. El caso más relevante es el de la e. f. 46. En el contenedor de materia orgánica, depositado en el interior de la cista, introdujeron una serie de objetos de adorno y de indumentaria, entre ellos un torques macizo sogueado y una lúnula. Por tanto, es probable que ambas piezas fueran exhibidas a la vez por el mismo individuo.

La condición de objetos excepcionales también convertía a las lúnulas, al igual que otros elementos de adorno e indumentaria, en marcadores sociales y económicos. Los ejemplares documentados corresponden preferentemente a tumbas de grandes dimensiones y/o con ajuares muy destacados, como sucede con las e. f. 28, 46, 149, 152, 154 y 170, aunque también se registran en algunas sepulturas con ajuares más modestos, como las e. f. 123, 155 y 174. Asimismo, por el aludido carácter exclusivo de estas piezas, debieron disfrutar de una especial consideración durante los rituales funerarios, como lo demuestra el hecho de haber recuperado diez de las dieciséis lúnulas identificadas dentro de los recipientes utilizados como urnas. Un patrón que se repite en la sepultura 7 de la necrópolis de La Torraza (Valtierra, Navarra) (Maluquer 1953: 254).

En lo que respecta a la relación que mantienen las lúnulas con el resto de objetos recuperados en los túmulos, el aspecto más relevante es la total ausencia de armas, que podría interpretarse como una pauta relacionada con cuestiones de género. No obstante, en algunos casos, sí aparecen asociadas a elementos que aparecen en tumbas preferentemente masculinas, como son los utensilios metálicos vinculados con ritos de sacrificio y banquete, en concreto a dos cuchillos en la e. f. 28, a un cazo en la e. f. 149 y a un cuenco de plata y una pátera de bronce en la e. f. 152.

Los ajuares de las sepulturas con lúnulas, salvo excepciones como las e. f. 123 y 155, presentan un importante número de elementos de indumentaria y 
adorno. Las fíbulas se registran en ocho de las nueve tumbas. El modelo de fíbula-placa es el más repetido, se cataloga en seis tumbas (e.f 46, 152, 154, 155, 170 y 174). Broches de cinturón se han encontrado en las e. f. 46, 152 y 154, a los que se une la lámina de refuerzo de la e. f. 149. En los objetos de adorno, además de las mencionadas cuentas de collar, destaca la presencia de piezas de orfebrería, tanto en oro como en plata, halladas en las e. f. 149 y 152.

Por último, también cabe reseñar la asociación a otros utensilios menos frecuentes en los ajuares de esta necrópolis, como las fusayolas de las e. f. 46 y 174 o la bola de piedra de la e. f. 155 .

En El Castillo se han clasificado lúnulas en todas las fases de ocupación identificadas en la necrópolis. Un hecho que, unido a los datos procedentes de las cercanas necrópolis de La Torraza (Valtierra, Navarra) y La Atalaya (Cortes, Navarra), demuestra la continuidad en el uso de lúnulas en el valle medio del Ebro entre los s. VI y III a. C., así como la trascendencia que estos objetos tuvieron en los rituales funerarios. Del análisis de las piezas también se deduce una evolución de los modelos, con la aparición de composiciones decorativas más complejas, en ocasiones figuradas, a partir de finales del s. VI o comienzos del s. v a. C.

\section{BIBLIOGRAFÍA}

Almagro Basch, M. 1972: "Los ídolos y la estela decorada de Hernán Pérez (Cáceres) y el ídolo estela de Tabuyo del Monte (León)", Trabajos de Prehistoria 29, 83-124.

Almagro-Gorbea, M. 1977: El Bronce Final y el Período Orientalizante en Extremadura, Madrid.

Almagro-Gorbea, M. 1995: "Ireland and Spain in the Bronze Age", J. Waddell y E. Shee (eds.), Ireland in the Bronze Age, Dublin, 136-148.

Almagro-Gorbea, M. y Lorrio, A. 2010: "El Heros Ktistes y los símbolos de poder de la Hispania prerromana", F. Burillo (coord.), Ritos y mitos: VI Simposio sobre los Celtíberos, Zaragoza, 157-182.

Almagro-Gorbea, M. y Lorrio, A. 2011: Teutates: el héroe fundador y el culto al antepasado en Hispania y en la Keltiké, Bibliotheca Archaeologica Hispana 36, Madrid.

Arévalo, A., Prados, L., Marcos, C. y Perea, A. 1998: "El origen votivo del tesoro de Salvacañete (Cuenca)”, C. Aranegui (coord.), Los Íberos. Príncipes de Occidente. Estructuras de poder de la sociedad Ibérica, Barcelona, 255-263.

Argente, J. L., Díaz, A., y Bescós, A. 2001: Tiermes V. Carratiermes. Necrópolis celtibérica, Arqueología en Castilla y León 9, Valladolid.

Atrián, P. y Martínez González, M. 1976: "Excavaciones en el poblado ibérico del Cabezo de la Guardia", Revista Teruel 55, 59-98.

Aura, J. E. y Segura, J. M. (coords.) 2000: Catálogo del Museo Arqueológico Municipal Camil Visedo Moltó (Alcoi, España), Alcoi.
Barril, M. 2003: "Cascos hallados en necrópolis celtibéricas conservados en el Museo Arqueológico Nacional de Madrid", Gladius 23, 5-60.

Barros, R. 1875: Antigüedades de Galicia, La Coruña.

Bonet, H., Llorens, M. M., Peréz, G. y Calvo, M. 1995: El Tossal de Sant Miquel de Llíria: la antigua Edeta y su territorio, Valencia.

Bonet, H., Soria, L. y Vives-Ferrándiz, J. 2011: "La vida en las casas. Producción doméstica, alimentación, enseres y ocupantes", H. Bonet y J. Vives-Ferrándiz (eds.), La Bastida de les Alcusses. 1928-2010, Valencia, 139-176.

Bosi, C., Garagnani, G. L., Martini, C., Morigi, C. y Bartolini, C. 2001: "La Situla della Certosa: studio diagnostico fializzato alla protezione e conservazione", La Metallurgia Italiana 7, 45-51.

Bueno, P. y Balbín, R. 1997: “Arte megalítico en sepulcros de falsa cúpula. A propósito del monumento de Granja de Toniñuelo (Badajoz)", Brigantium 10, 91-121.

Cabré Aguiló, J. 1939-1940: "La Caetra y el Scutum en Hispania durante la Segunda Edad del Hierro", Boletín del Seminario de Estudios de Arte y Arqueología 6, 5-83.

Cabré Aguiló, J. 1944: Corpus Vasorum Hispanorum. Museos Arqueológicos de Madrid, Barcelona y Zaragoza. Cerámica de Azaila, Madrid.

Castiella, A. 2007: "El poblado y la necrópolis de la I Edad del Hierro en Valtierra (Navarra)", Cuadernos de Arqueología de la Universidad de Navarra 15, 193-243.

Celestino, S. 2001: Estelas de guerrero y estelas diademadas. La precolonización y formación del mundo tartésico, Barcelona.

Chapa, T. 1985: "Una escultura ibérica de cérvido procedente de Higueruela", Basīt: al- Basīt 11, 85-94.

Chapa, T. y Olmos, R. 2004: "El imaginario del joven en la cultura ibérica", Melánges de la Casa de Velázquez, Nouvelle Serie 34, 1, 43-83.

Comendador, B. 1998: "Los inicios de la metalurgia en el noroeste de la Península Ibérica", Brigantium 11, 1-262.

Corzo, R. 2004: "Sobre la imagen de Hercules Gaditanus", Romula 3, 37-62.

Díaz Ariño, B., Leorza, R. y Mayayi, A. 2011: "Una cerámica de la Primera Edad del Hierro con decoración zoomorfa procedente del cabezo del Lugar (Azaila, Teruel)", Paleohispanica 11, 109-125.

Dumézil, G. 1954: Rituels indo-européens à Rome, Paris.

Faro, J. A. 2002: "Protohistoria", A. García Paredes (coord.), Castejón, cuatro milenios de Historia, Castejón, 28-38.

Faro, J. A. 2015: "La necrópolis de El Castillo (Castejón, Navarra). Vajilla e instrumental metálico de sacrificio y banquete en el valle medio del Ebro (s. VI - III a. C.)", Lvcentvm 34, 1-88. https://doi.org/10.14198/lvcentvm2015.34.03

Faro, J. A., Cañada, F. y Unzu, M. 2002-2003: "Necrópolis de El Castillo (Castejón. Navarra). Primeras valoraciones, campañas 2000-2001-2002”, Trabajos de Arqueología Navarra 16, 45-77.

Faro, J. A. y Unzu, M. 2006: "La necrópolis de la Edad del Hierro de El Castillo (Castejón. Navarra). Primeras valoraciones: campañas 2000-2002", Complutum 17, 145-166.

Fletcher, D. 1977: La necrópolis ibérica del Corral de Saus (Mogente, Valencia), Valencia.

García Paredes, A. 2002: "Prólogo", A. García Paredes (coord.), Castejón, cuatro milenios de Historia, Castejón, 19-21.

García Vuelta, O. y Armada, X. L. 2003: "Documentación arqueológica del oro castreño: acerca de F. Maciñeira y el 
torques de Capelada (San Xiao de Montoxo, Cedeira, A Coruña)", Brigantium 14, 117-138.

Gomes, M. V. 1997: "Estátuas-menires antropomórficas do AltoAlentejo. Descobertas recentes e problemática”, Brigantium $10,255-279$.

Gomes, M. V. 2011: "Estátuas-menires antropomórficas da Região de Évora. Novos testemunhos e problemáticas", IV Jornadas Rainas Estelas e estátuas-menires da Pré à Protohistória, Sagubal, 11-36.

Gonçalves, V., Andrade, M. y Pereira, A. 2004: "As placas de xisto gravadas das grutas artificais do Toja de Vila Chã (Carenque) e da Necrópole das Baútas (Mina, Amadora)", O Arqueólogo Português 22, 113-162.

Graells, R. y Lorrio, A. 2013: "El casco celtibérico de Muriel de la Fuente (Soria) y los hallazgos de cascos en las aguas en la península ibérica", Complutum 24, 1, 151-173. https:// doi.org/10.5209/rev_cmpl.2013.v24.n1.42329

Graells, R, Lorrio, A. y Quesada, F. 2014: Cascos hispanocalcídicos. Símbolos de las élites guerreras celtibéricas, Römisch-Germanisches Zentralmuseum K46, Mainz.

Izquierdo, I. 1998-1999: "Las damitas de Moixent en el contexto de la plástica y la sociedad ibérica”, Lucentum 17-18, 131148. https://doi.org/10.14198/lvcentvm1998-1999.17-18.06

Izquierdo, I. 2007: "Arqueología de la muerte y el estudio de la sociedad: Una visión desde el género en la Cultura Ibérica", Complutum 18, 247-261.

Jimeno, A.; Torre, J. I.; Berzosa, R y Martínez, P. 2004: La necrópolis celtibérica de Numancia, Arqueología en Castilla y León 12, Soria.

Juan i Moltó, J. 1987-1988: "El conjunt de terracotes votives del Santuari ibèric de la Serreta (Alcoi, Cocentaina, Penàguila)", Saguntum 21, 295-329.

Lorrio, A. y Royo J. I. 2013: "El guerrero celtibérico de Mosqueruela (Teruel): una pintura rupestre excepcional de la Edad del Hierro en el Alto Maestrazgo turolense", Antiquitas 25, 85-108.

Lorrio, A. y Sánchez de Prado, Ma . D. 2009: La necrópolis celtibérica de Arcóbriga (Monreal de Ariza, Zaragoza), Caesaraugusta 80, Zaragoza.

Lucas, $M^{a}$ R. 1990: "Trascendencia del tema del labrador en la cerámica ibérica de la provincia de Teruel", Zephyrvs 43, 293-303.

Macdonald, P. 2007: Llyn Cerrig Bach: A study of the Copper Alloy Artefacts from the Insular La Tène Asemblage, Cardiff.

Maluquer, J. 1953: "La necrópolis de la Edad del Hierro de La Torraza, en Valtierra (Navarra)", Príncipe de Viana 14, 243-269.

Maluquer, J. 1970: "Desarrollo de la orfebrería prerromana en la Península Ibérica", Pyrenae 6, 79-109.

Maluquer, J. y Vázquez de Parga, L. 1956: "Avance del estudio de la necrópolis de La Atalaya, Cortes de Navarra", Príncipe de Viana 17, 389-454

Marco, F. 1989: "Lengua, instituciones y religión de los celtíberos", G. Fatás (ed.), Los Celtas en el Valle Medio del Ebro, Zaragoza, 99-129.

Marco, F. y Royo, J. I. 2012: "Iconografía entre la Primera Edad del Hierro y la romanización: nuevos documentos y

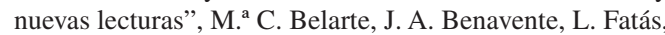
J. Diloli, P. Moret y J. Noguera (eds.), Iberos del Ebro. Actas del II Congreso Internacional (Alcañiz-Tivissa, 16-19 de noviembre de 2011), Tarragona, 305-320.

Moneo, T. 2003: Religio Ibérica. Santuarios, ritos y divinidades ( s. VII - I a. C.), Bibliotheca Archaeologica Hispana 20, Madrid.
Negueruela, I. 1990: Los monumentos escultóricos Ibéricos del Cerrillo Blanco de Porcuna (Jaén): estudio sobre su estructura interna, agrupamientos e interpretación, Madrid.

Olmos, R. 2000: "El vaso del 'ciclo de la vida' de Valencia: una reflexión sobre la imagen metafórica en época iberohelenística", Archivo Español de Arqueología 73, 59-85. https://doi.org/10.3989/aespa.2000.v73.318

Olmos, R. y Grau, I. 2005: "Vas dels Guerrers de La Sereta", Recerques del Museu d'Alcoi 14, 78-98.

Palol, P. 1943: "La necrópolis hallstáttica de Agullana", Ampurias 5, 260-267.

Pastor, J. M. 2010: "Doble espiral y eses en serie: símbolos gráficos de 'cadencia' en las culturas ibérica y celtibérica", F. Burillo (coord.), Ritos y mitos: VI Simposio sobre los Celtíberos, Zaragoza, 473-484.

Pérez Vilatela, L. 2009: "Iconología e ideología en los reversos monetales de Ikalkumsken”, Estudios de lenguas y epigrafía antiguas 9, 61-114.

Pilloy, J. 1899: Les tertres funéraires d'Avezac-Prat, Paris.

Plá, E. 1951-1952: "Un arado ibérico votivo. Notas sobre los arados antiguos", Saitabi 8, 12-27.

Quesada, F. 1989: "La utilización del arco y las flechas en la cultura ibérica", Trabajos de Prehistoria 46, 161-201. https://doi.org/10.3989/tp.1989.v46.i0.593

Quesada, F. 1997: El armamento ibérico. Estudio tipológico, geográfico, funcional, social y simbólico de las armas en la Cultura Ibérica (siglos VI-I a. C.), Instrumentum 3, Montagnac.

Raddatz, K. 1969: Die Schatzfunde der Iberischen Halbinsel, Berlin.

Romero, F. 1999: "El vaso de los guerreros de Numancia", Revista de Soria 25, 51-66.

Ruiz Zapatero, G. 1985: Los Campos de Urnas del N. E. de la Península Ibérica, Tesis Doctoral policopiada, Universidad Complutense de Madrid.

San Nicolás, M. P. 1986: "Orfebrería púnica: los collares de Ibiza en el Museo Arqueológico Nacional”, Saguntum 20, 57-94.

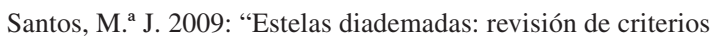
de clasificación", Herakleion 2, 7-40.

Sanz Mínguez, C. 1997: Los Vacceos: cultura y ritos funerarios de un pueblo prerromano del valle medio del Duero. La necrópolis de Las Ruedas, Padilla de Duero (Valladolid), Salamanca.

Sarlegui, L. 1894: Estudios sobre la época céltica en Galicia, Ferrol.

Schulten, A. 1931: Numantia: dei Ergebnisse der Ausgrabungen, II, Die Stadt Numantia, München.

Serra-Ràfols, J. de C. 1941: "El poblado ibérico del Castellet de Banyoles (Tivissa-Bajo Ebro)", Ampurias 3, 15-34.

Silva, A. C. F. 1986: A cultura castreja no Noroeste de Portugal, Paços de Ferreira.

Sopeña, G. 1987: Dioses, ética y ritos. Aproximaciones para una comprensión de la religiosidad entre los pueblos celtibéricos, Zaragoza.

Sousa, F. 2007: Introducción a la historia de la indumentaria en España, Madrid.

Vilaseca, S. 1956: "El campo de urnas de La Tosseta (Guiamets, prov. de Tarragona)", IV Congreso Internacional de Ciencias Prehistóricas y Protohistóricas, Madrid, 841-856.

Recibido: 25-05-2016

Aceptado: 07-12-2016 